\title{
Prognostic Prediction of Tracer Dispersion for the Diablo Canyon Experiments on August 31, September 2, and September 4, 1986
}

\author{
C.R. Molenkamp
}

November 29, 1999

U.S. Department of Energy

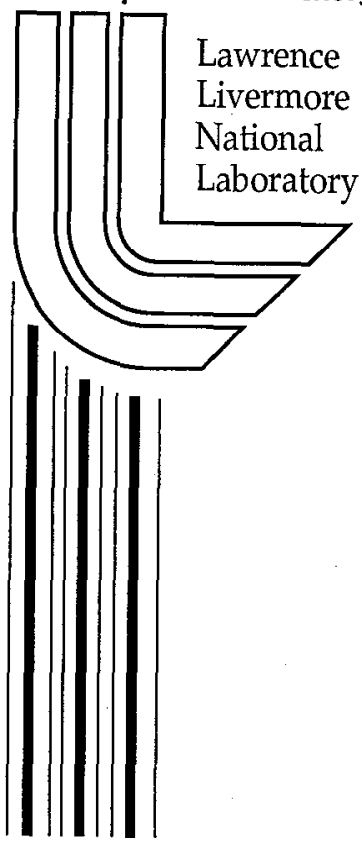




\section{DISCLAIMER}

This document was prepared as an account of work sponsored by an agency of the United States Government. Neither the United States Government nor the University of California nor any of their employees, makes any warranty, express or implied, or assumes any legal liability or responsibility for the accuracy, completeness, or usefulness of any information, apparatus, product, or process disclosed, or represents that its use would not infringe privately owned rights. Reference herein to any specific commercial product, process, or service by trade name, trademark, manufacturer, or otherwise, does not necessarily constitute or imply its endorsement, recommendation, or favoring by the United States Government or the University of California. The views and opinions of authors expressed herein do not necessarily state or reflect those of the United States Government or the University of California, and shall not be used for advertising or product endorsement purposes.

Work performed under the auspices of the U. S. Department of Energy by the University of California Lawrence Livermore National Laboratory under Contract W-7405-Eng-48.

This report has been reproduced directly from the best available copy.

Available to DOE and DOE contractors from the

Office of Scientific and Technical Information

P.O. Box 62, Oak Ridge, TN 37831

Prices available from (423) 576-8401

http://apollo.osti.gov/bridge/

Available to the public from the

National Technical Information Service

U.S. Department of Commerce 5285 Port Royal Rd., Springfield, VA 22161

http://www.ntis.gov/

OR

Lawrence Livermore National Laboratory Technical Information Department's Digital Library http://www.llnl.gov/lid/Library.html 


\title{
Prognostic Prediction of Tracer Dispersion for the Diablo Canyon Experiments on August 31, September 2, and September 4, 1986
}

\author{
Charles R. Molenkamp
}

Lawrence Livermore National Laboratory

P.O. Box 808

Livermore, CA 94551 


\section{Table of Contents}

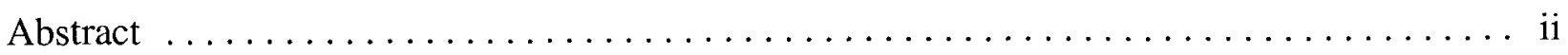

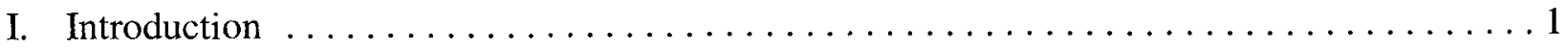

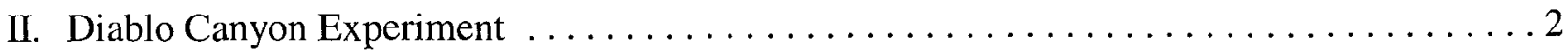

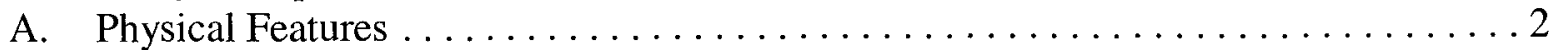

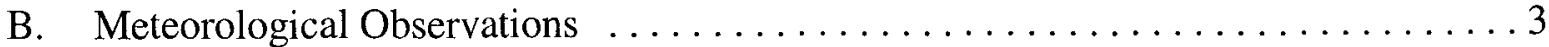

C. Tracer Releases . . . . . . . . . . . . . . . . . . . . . . . . . 4

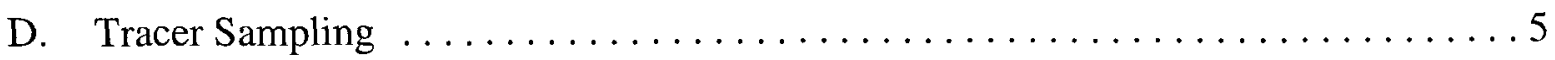

III. Models . . . . . . . . . . . . . . . . . . . . . . . . . . . . 6

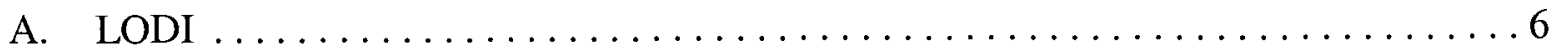

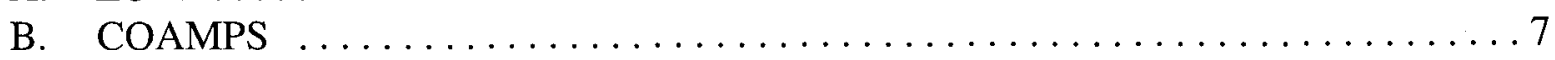

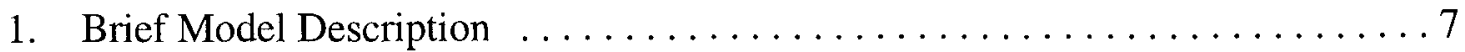

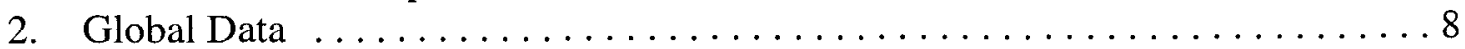

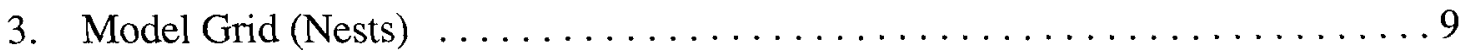

4. Update Cycle (Optimal Interpolation) $\ldots \ldots \ldots \ldots \ldots \ldots \ldots \ldots \ldots \ldots \ldots \ldots \ldots \ldots \ldots$

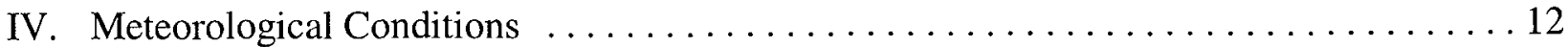

A. August 31,1986 - Strong synoptic forcing $\ldots \ldots \ldots \ldots \ldots \ldots \ldots \ldots \ldots \ldots \ldots \ldots$

B. September 2,1986 - Weak southerly synoptic forcing $\ldots \ldots \ldots \ldots \ldots \ldots \ldots$

C. September 4, 1986 - Weak northerly synoptic forcing $\ldots \ldots \ldots \ldots \ldots \ldots \ldots$

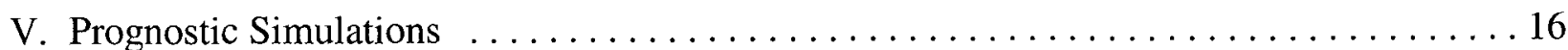

A. Description of COAMPS Simulation Procedure $\ldots \ldots \ldots \ldots \ldots \ldots \ldots \ldots$

B. Description of LODI Procedure $\ldots \ldots \ldots \ldots \ldots \ldots \ldots \ldots \ldots \ldots \ldots \ldots \ldots \ldots$

C. Predicted Concentrations and Comparison to Tracer Samples . . . . . . . . . 18

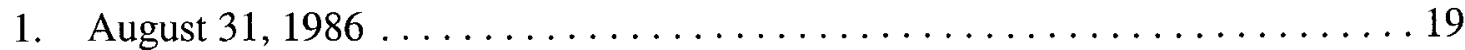

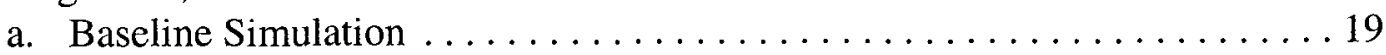

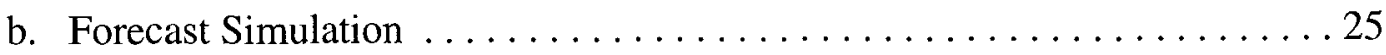

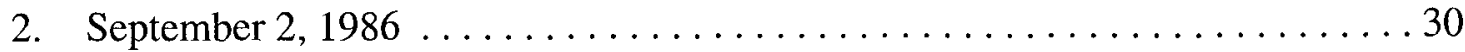

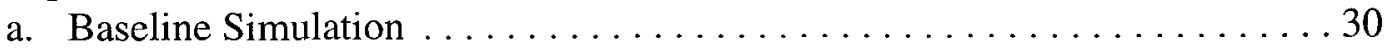

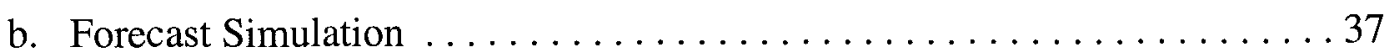

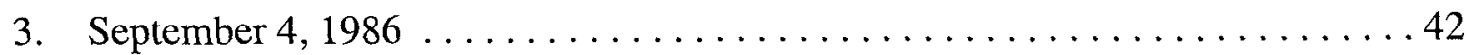

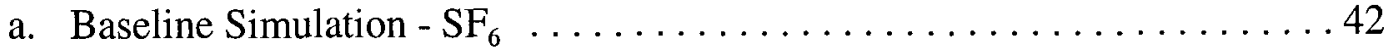

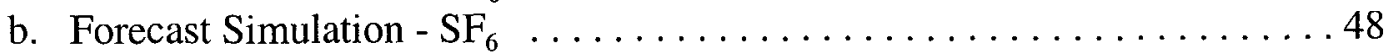

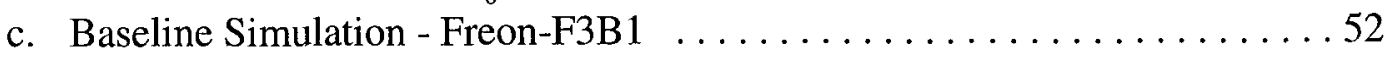

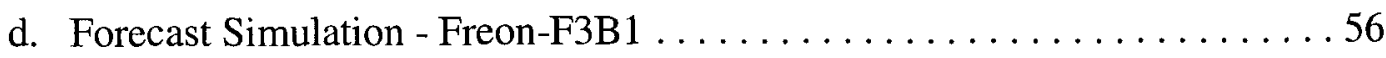

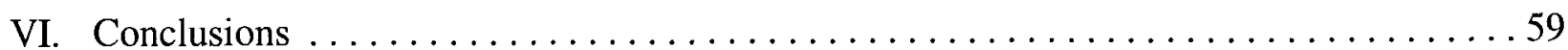

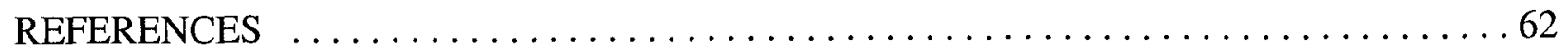




\begin{abstract}
COAMPS/LODI simulations of the tracer experiments at Diablo Canyon on August 31, September 2, and September 4, 1986 had mixed results. Simulated tracer concentrations on August 31 differed significantly from the measured concentrations. The model transported $\mathrm{SF}_{6}$ too far south and did not predict transport of $\mathrm{SF}_{6}$ north along highway 101 or into See Canyon. Early in the day the model rapidly transported $\mathrm{SF}_{6}$ away from the release point while observations suggested the tracer stayed close to Diablo Canyon for 1-2 hours. For September 2, simulations agreed very well with the measurements. The model accurately predicted the change of wind direction from north northwest to east northeast at the release point. It also predicted the advection of tracer over Morro Bay and through the Los Osos Valley toward San Luis Obispo in excellent agreement with the observations. On September 4, the calculated transport of $\mathrm{SF}_{6}$ from Diablo Canyon had defects similar to those on August 31, a trajectory too far south and limited intrusion of tracer north along highway 101. Conversely, simulations of the Freon release from Los Osos Cemetery on September 4 corresponded well with observations. Since the simulations used only global meteorological data and no local winds for input, even the limited success of
\end{abstract} COAMPS/LODI is a favorable result.

COAMPS's inability to generate southerly winds through the highway 101 corridor on August 31 and September 4 is a symptom of its underestimate of the sea breeze. The weak sea breeze correlates with a small diurnal range of air temperature possibly associated with underestimates of surface solar heating and/or overestimates of surface wetness. 
Improvement of COAMPS/LODI simulations requires development of new data assimilation techniques to use the local surface and low altitude wind and temperature measurements. Also, quantitative methods are needed to assess the accuracy of the models. 


\section{Prognostic Prediction of Tracer Dispersion for the Diablo Canyon Experiments on August 31, September 2, and September 4, 1986}

\section{Introduction}

Accidental and intentional releases of toxic, hazardous, and radioactive substances are a significant risk for citizens and residents of the United States. Use of chemical and biological agents by terrorists has become an increasing threat in the post cold war era. In response to this danger, we are improving our state-of-the-art capability to calculate pollutant transport and dispersion in the atmosphere by combining leading-edge local and regional scale atmospheric models with new wind field and transport and diffusion models and validating this capability with observational data and field experiments. We then integrate this capability into a system that can respond to accidents, threats, and intentional releases quickly.

During August and September, 1986 a series of tracer release experiments was conducted near the Diablo Canyon Nuclear Power Plant along the California coast that we call the Dopptex Experiments (Thuillier 1987, 1988a, 1988b, 1988c). In this paper we describe our first attempts to predict the dispersion of tracer releases on August 31, September 2, and September 4, 1986 using a prognostic mesoscale model to define the wind fields. We previously calculated tracer dispersion for August 31, 1986 using our diagnostic method for prescribing the wind field.

A diagnostic model determines the wind field by extrapolating observed horizontal winds to a grid and then estimating the three-dimensional flow field using a mass consistency constraint over the local topography. This flow field is then assumed to transport trace material until the next set of wind obscrvations are available and can be analyzed. Conscquently, the diagnostic 
technique is incapable of predicting the evolution of the flow field. In addition, wind observations are generally made near the surface. With only a few widely spaced vertical soundings and the weakness of not including local thermal forcing, the diagnostic model has a limited capability for generating three-dimensional winds.

A prognostic model, on the other hand, integrates the three-dimensional equations of motion for the atmosphere forward in time from a prescribed initial state to provide estimates of the future state of the atmosphere. Thus, a prognostic model is inherently predictive. In a region such as the California coast where there is significant thermal forcing and marked diurnal variability, a prognostic model has a much greater chance of accurately estimating the flow field. At LLNL we are using the Naval Research Laboratory's (NRL) nonhydrostatic mesoscale model, COAMPS (Hodur 1997), to predict the wind field.

\section{Diablo Canyon Experiment}

\section{A. Physical Features}

Diablo Canyon is in a fairly remote section of the Pacific coast of California west of San Luis Obispo. The terrain is very rugged with elevations of more than $400 \mathrm{~m}$ less than $2 \mathrm{~km}$ from the ocean. Terrain is plotted in Figure 1 and profiled in Figure 2. During September the California coast is generally under the influence of a high pressure region over the eastern Pacific Ocean. Associated with this weather regime are a marine layer and low-level inversion providing a stable thermal stratification. The large-scale wind is generally from the northwest. Strong solar heating over land promotes development of a sea breeze during the day. Steep topography not only channels the flow, but also permits the development of drainage flows at night and upslope 


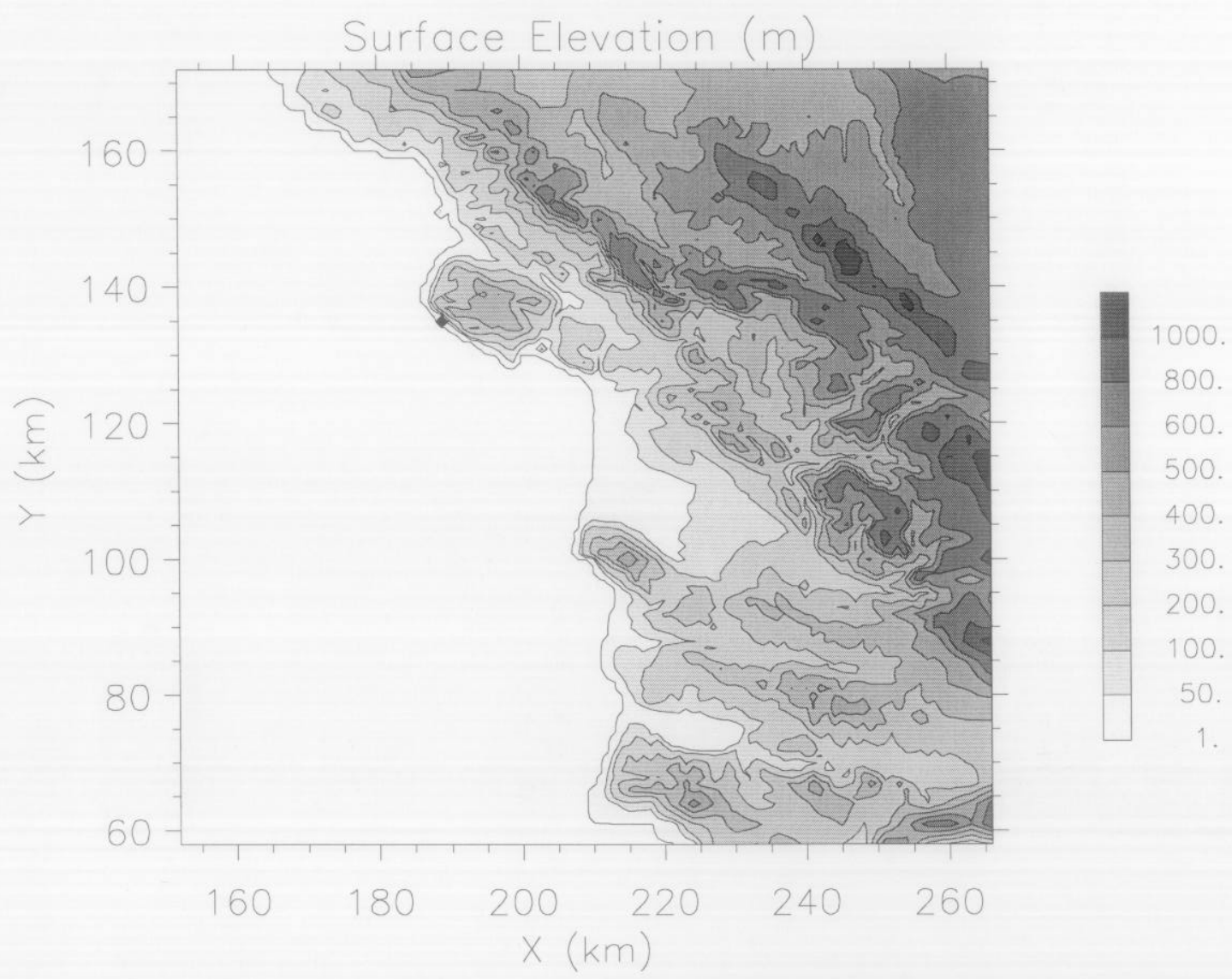

Figure 1. Topography of the California coast near Diablo Canyon $(x, y=189,135=120.8536 \mathrm{~W}$, $35.2118 \mathrm{~N}$ ). The $\mathrm{x}$ and $\mathrm{y}$ coordinates are $\mathrm{km}$ from an arbitrary point.

motion during the day. Consequently, this region has complex and often locally forced meteorology that provides a challenging test for numerical models.

\section{B. Meteorological Observations}

The tracer experiment was supported by standard meteorological data available in the region (five National Weather Service and local airport sites, and six San Luis Obispo County Air Pollution Control District sites) and several sensors associated with the power plant. The additional sensors associated with the Diablo Canyon Power Plant include three Doppler acoustic sounders, two taller meteorological towers and five $10 \mathrm{~m}$ towers that all measure the wind, its 


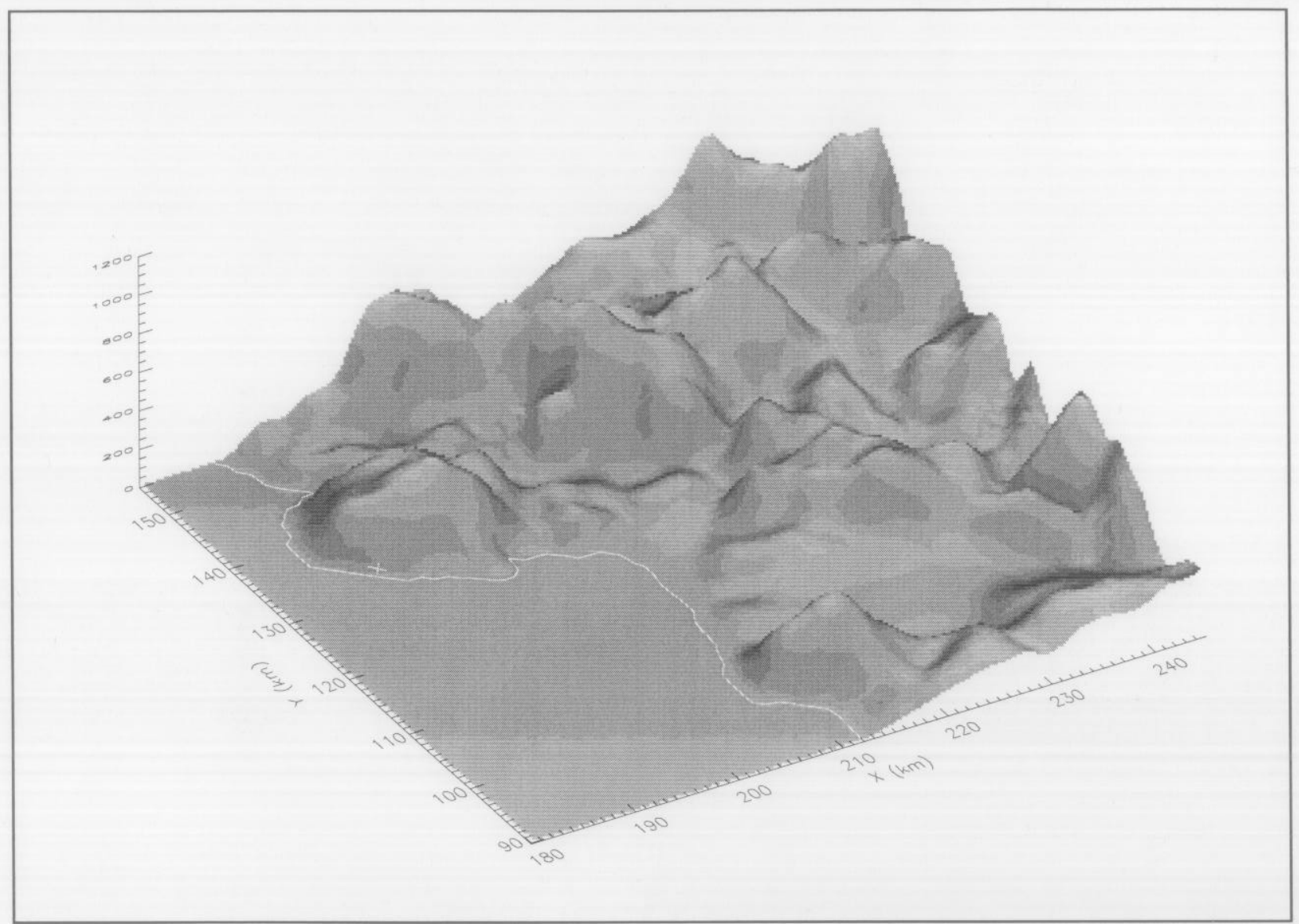

Figure 2. Model topography near Diablo Canyon. Heights are in m. Diablo Canyon Power Plant is marked by $\mathrm{X}$. The $\mathrm{x}$ and $\mathrm{y}$ coordinates are $\mathrm{km}$ from an arbitrary point. The solid white line is the coastline. This plot shows a subset of the area in Figure 1.

variability and several other meteorological variables. Locations of the meteorological stations and the tracer release points are shown in Figure 3.

\section{Tracer Releases}

Inert tracers were released during eight days from August 31 to September 17, 1986. The tracers were sulfur hexafluoride $\left(\mathrm{SF}_{6}\right)$ and Freon-F3B1. Tracer releases started at 15:00 UTC (8am PDT) and continued, sometimes intermittently, throughout the day until 23:00 UTC (4pm PDT). Tracers were released from the Diablo Canyon Power Plant, D, (35.2118 N, 


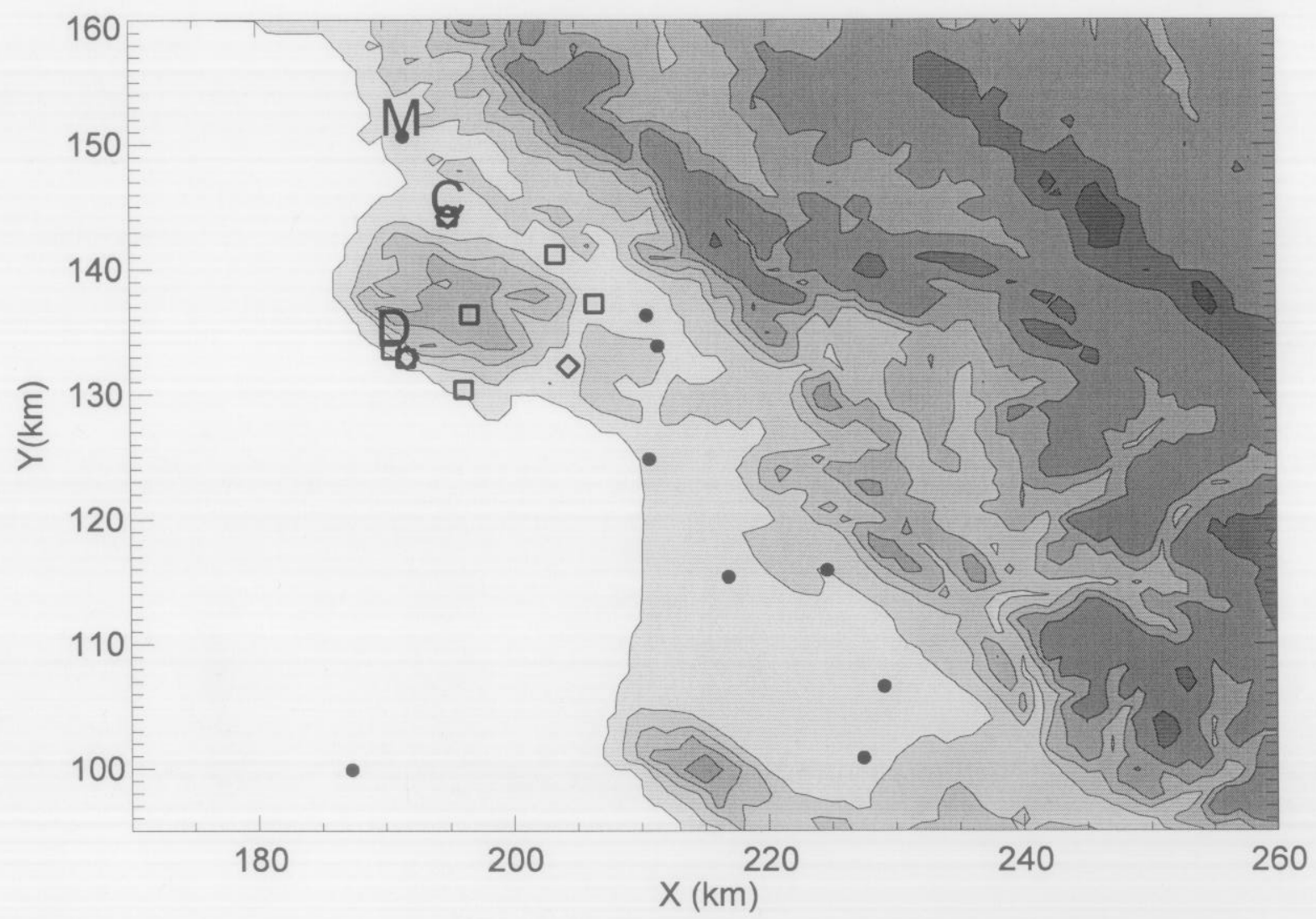

Figure 3. Tracer release points and meteorological stations. The release points are indicated by D, $\mathrm{M}$ and $\mathrm{C}$. The Doppler sounder locations are indicated by $\diamond$, the tower sites by $\square$, and the surface meteorology sites by $\bullet$. Two of the Doppler sounders are co-located with towers. Two surface sites, Point Piedras Blancas and Paso Robles, are off the map at $(\mathrm{x}, \mathrm{y})=(152,183)$ and $(209,184)$.

120.8536 W), Morro Bay Power Plant, M, (35.3669 N, 120.8410 W), and Los Osos Cemetery, $\mathrm{C},(35.3060 \mathrm{~N}, 120.8024 \mathrm{~W})$. The schedule of experiments and tracer releases is given in

Table 1. Tracer experiments were not conducted on consecutive days.

\section{Tracer Sampling}

The air sampling network for measuring tracer concentrations consisted of 150 surface stations located within about $35 \mathrm{~km}$ of the Diablo Canyon Power Plant. "Sampling sites were selected for the purpose of defining the paths and spatial extent of the plumes as they passed 


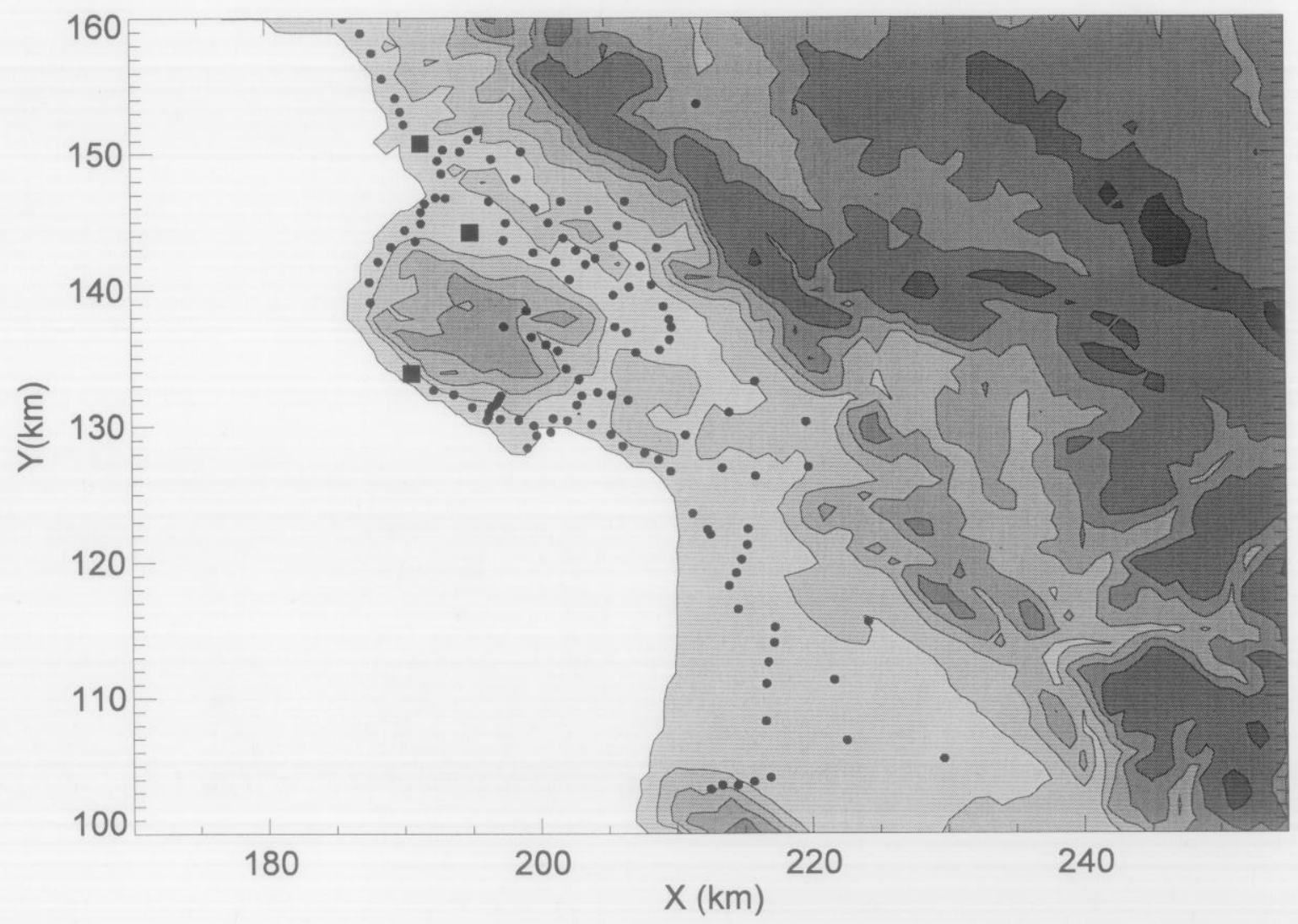

Figure 4. Location of the Dopptex Samplers. Circles are the sampler sites. Squares are the release sites. Shaded contours show the smoothed terrain for the COAMPS inner nest at $100 \mathrm{~m}$ intervals.

around and over terrain features. Special attention was given to the valley mouths and terrain gaps expected to provide the principal transport paths." (Thuillier 1988a, pg. 2-10) Sampler sites are shown in Figure 4. On experimental days hourly average tracer concentrations were obtained for each sampler from the start of the release until three hours after the release ended, $i$. e., from 15:00 UTC (8am PDT) until 02:00 UTC the next day (7pm PDT).

\section{Models}

\section{A. LODI}

The new Livermore Operational Dispersion Model, LODI, (Leone et al. 1998) is being developed for operational emergency response within the U.S. Department of Energy's National 
Atmospheric Release Advisory Capability (NARAC). It is an atmospheric dispersion model that solves the three-dimensional advection diffusion equation using a Lagrangian stochastic, Monte Carlo method. The Lagrangian stochastic approach calculates possible trajectories of fluid "particles" in a turbulent flow. Fluid "particles" are marked at the source with an appropriatc amount of contaminant mass. A large number of independent particle trajectories are calculated, i. e., a large number of "particles" are moved in response to the various processes represented in the simulation, and the mean contaminant air concentration is estimated from the spatial distribution of the particles at a particular time.

The two most important processes for inert tracers are advection by the mean wind and dispersion by turbulent motions. To calculate advection, three-dimensional gridded mean wind fields from a diagnostic model or a prognostic model, such as COAMPS, are read into LODI. Turbulent dispersion is modeled via random diffusive movements using atmospheric eddy diffusion (K) parameterizations. Radioactive decay, first-order chemical reactions, and wet and dry deposition of a pollutant also can be simulated. (Leone et al. 1998)

\section{B. COAMPS}

\section{Brief Model Description}

The Naval Research Laboratory (NRL) has developed the Coupled Ocean/Atmosphere Mesoscale Prediction System (COAMPS), a numerical model consisting of oceanic and atmospheric components coupled at the surface. Hodur (1997) describes the model in detail.

In our simulations we use only the atmospheric component, which solves the nonhydrostatic, fully compressible equations of motions using a time-splitting method (Klemp and Wilhelmson 1978). It includes parameterizations for subgrid-scale mixing (Deardorff 1980), surface fluxes 
(Louis et al. 1982), explicit moist physics (Rutledge and Hobbs 1983), cumulus processes (Kain and Fritsch 1990, 1993), and radiation (Harshvardan et al. 1987). The finite difference equations use the Arakawa $\mathrm{C}$ grid; four map projections (Lambert conformal, polar stereographic, Mercator, and spherical) are supported. The vertical coordinatc is a scaled height, $\sigma$,

$$
\sigma=Z_{t o p}\left(\frac{z-z_{s f c}}{z_{\text {top }}-z_{s f c}}\right)
$$

where $z_{\text {top }}$ is the depth of the model domain and $z_{s f c}$ is the terrain height.

Surface conditions must be set from a previous COAMPS run or interpolated from either a global model or a climatological data base. These surface properties are terrain height, surface albedo, surface roughness, ground wetness, and ground temperature. Initial conditions for model variables come from either a previous COAMPS run or a global model. COAMPS also has a data assimilation system consisting of quality control, multivariate optimal interpolation analysis, and initialization modules that allow incorporation of observations into the specification of the initial fields. At the horizontal boundary, time varying conditions are specified based on a global model forecast.

\section{Global Data}

The standard version of COAMPS expects global data and forecasts from NRL's general circulation model, NOGAPS (Hogan and Rosmond 1991). Since no archived NOGAPS data are available for the DOPPTEX experiment dates, we obtained reanalysis data from NCEP (Kalnay et al. 1996) and ECMWF (http://www.ecmwf.int/data/reanalysis.html) global reanalysis projects 
and modified COAMPS to use these data.

These reanalyses are available at 6-hour

intervals $(00,06,12,18$ UTC) on a global

grid with 2.5 degree horizontal resolution.

The three-dimensional fields are given on pressure levels as shown in Table 2.

\section{Model Grid (Nests)}

COAMPS uses nested grids to reach

the needed resolution with a $3: 1$ ratio

between nests. For the DOPPTEX

Experiments, the spacing of the tracer

observations and the scale of the

atmospheric flow field is about $1 \mathrm{~km}$. To

reach this scale from the 2.5 degree

resolution of the global data $(\sim 250 \mathrm{~km})$

requires five nests with properties as

given in Table 3 . Since we were only

concerned with wind fields in the inner nest, we chose

each outer nest to be just large enough to contain the

next inner nest and the necessary boundary transition

points (nine grid points in the inner nest or three in the
Table 2. Global Model Pressure Levels

\begin{tabular}{|c|c|c|c|}
\hline \multirow{2}{*}{$\begin{array}{l}\text { Level } \\
(\mathrm{mb})\end{array}$} & \multicolumn{3}{|c|}{ Model } \\
\hline & NOGAPS & NCEP & ECMWF \\
\hline 0.4 & $\mathrm{x}$ & & \\
\hline 1.0 & $\mathrm{x}$ & & \\
\hline 2.0 & $\mathrm{x}$ & & \\
\hline 5.0 & $\mathrm{x}$ & & \\
\hline 10.0 & $\mathrm{x}$ & $\mathrm{x}$ & $\mathrm{x}$ \\
\hline 20.0 & $\mathrm{x}$ & $\mathrm{x}$ & \\
\hline 30.0 & $\mathrm{x}$ & $x$ & $\mathrm{x}$ \\
\hline 50.0 & $\mathrm{X}$ & $\mathrm{x}$ & $\mathrm{x}$ \\
\hline 70.0 & $\mathrm{x}$ & $\mathrm{x}$ & $\mathrm{x}$ \\
\hline 100.0 & $\mathrm{x}$ & $\mathrm{x}$ & $\mathrm{x}$ \\
\hline 150.0 & $\mathrm{x}$ & $\mathrm{x}$ & $\mathrm{x}$ \\
\hline 200.0 & $\mathrm{x}$ & $\mathrm{x}$ & $\mathrm{x}$ \\
\hline 250.0 & $\mathrm{x}$ & $\mathrm{x}$ & $\mathrm{x}$ \\
\hline 300.0 & $\mathrm{x}$ & $\mathrm{x}$ & $\mathrm{x}$ \\
\hline 400.0 & $\mathrm{x}$ & $\mathrm{x}$ & $\mathrm{x}$ \\
\hline 500.0 & $\mathrm{x}$ & $\mathrm{x}$ & $\mathrm{x}$ \\
\hline 600.0 & & $\mathrm{x}$ & $\mathrm{x}$ \\
\hline 700.0 & $\mathrm{x}$ & $\mathrm{x}$ & $\mathrm{x}$ \\
\hline 775.0 & & & $\mathrm{x}$ \\
\hline 850.0 & $\mathrm{x}$ & $\mathrm{x}$ & $\mathrm{x}$ \\
\hline 925.0 & $\mathrm{x}$ & $\mathrm{x}$ & $\mathrm{x}$ \\
\hline 1000.0 & $x$ & $\mathrm{x}$ & $\mathrm{x}$ \\
\hline
\end{tabular}

Table 3. COAMPS Nests for DOPPTEX Simulations

\begin{tabular}{ccc}
\hline Nest & $\begin{array}{c}\Delta \mathrm{x} \\
(\mathrm{km})\end{array}$ & $\begin{array}{c}\text { Number of grid } \\
\text { points }\end{array}$ \\
\hline 1 & 81 & 30 \\
2 & 29 & 34 \\
3 & 9 & 40 \\
4 & 3 & 58 \\
5 & 1 & 115 \\
\hline
\end{tabular}


outer nest). We used only one-way interaction from larger to smaller nests.

Diablo Canyon Power Plant, the primary tracer release point, was placed northwest of the grid center because the winds are typically from the northwest. The five nested are shown in Figure 5.

The vertical resolution is the same for all nests. In these simulations we used 31 vertical layers with highest resolution near the ground. The heights at the top of the layers are 10, 30, 60, $100,150,225,350,500,750,1000,1300,1600,2000,2500,3100,3800,4600,5500,6500$, $7500,8500,9250,10000,10750,11500,12500,13500,15000,18000,24000,33000 \mathrm{~m}$.

\section{Update Cycle (Optimal Interpolation)}

For the Diablo Canyon tracer releases on August 31, September 2, and September 4, 1986 described in this paper, COAMPS was initialized with ECMWF global reanalysis data at 06

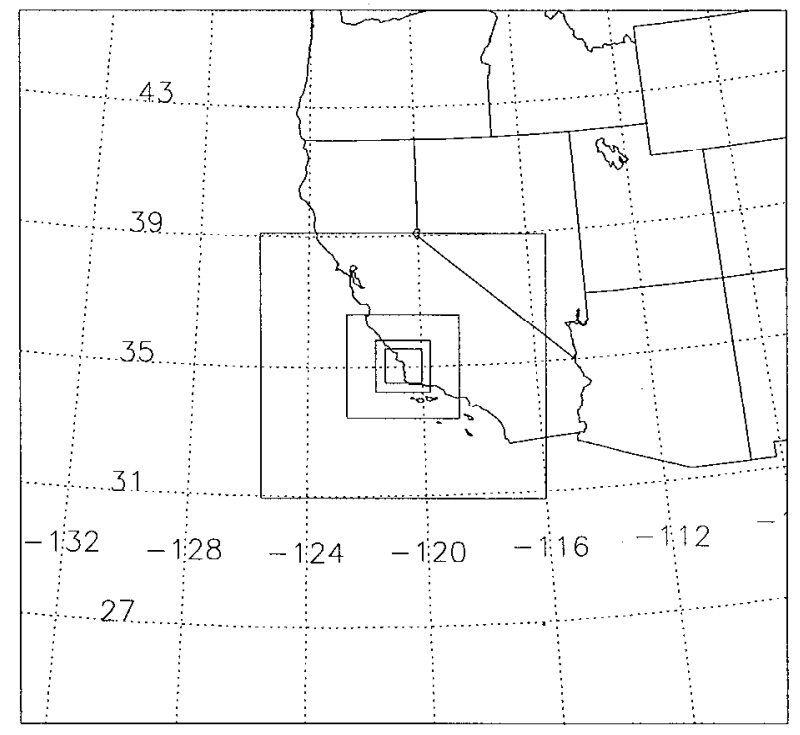

Figure 5a. COAMPS grid for DOPPTEX Experiment showing all nests. The outer COAMPS nest covers the entire domain; the inner nests are indicated by the boxes.

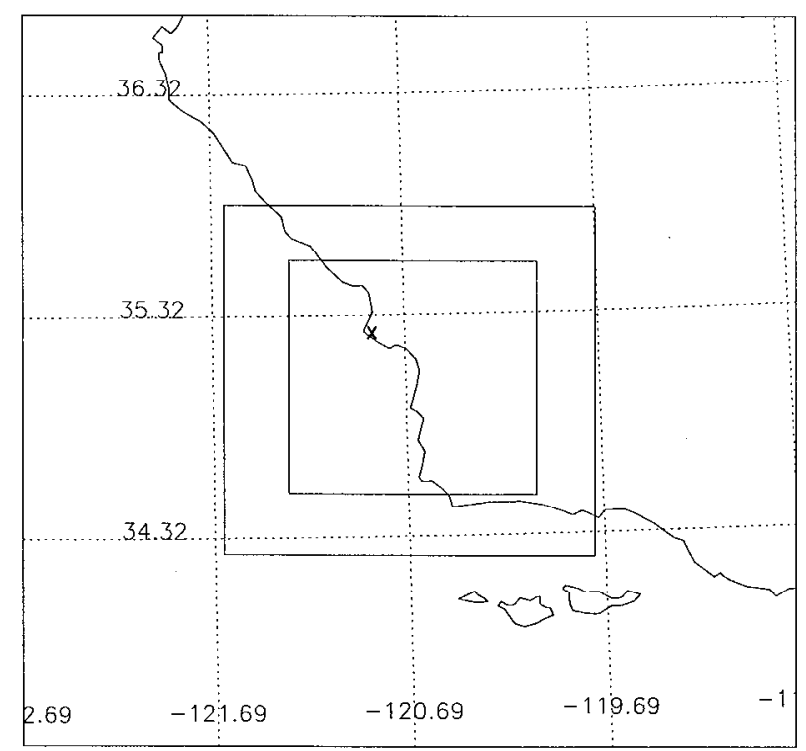

Figure 5b. COAMPS grid for DOPPTEX Experiment showing the inner 3 nests. $X$ marks the Diablo Canyon Power Plant. 
UTC. At initialization the global fields were interpolated to all nests. The nine hours of simulation before the release is to allow the model to spin up to representative conditions on all nests.

Every six hours a new set of global reanalysis data is available. We use this data to perform an update cycle using the multivariate optimum interpolation (MVOI) module (Lorenc 1986) in COAMPS. For an

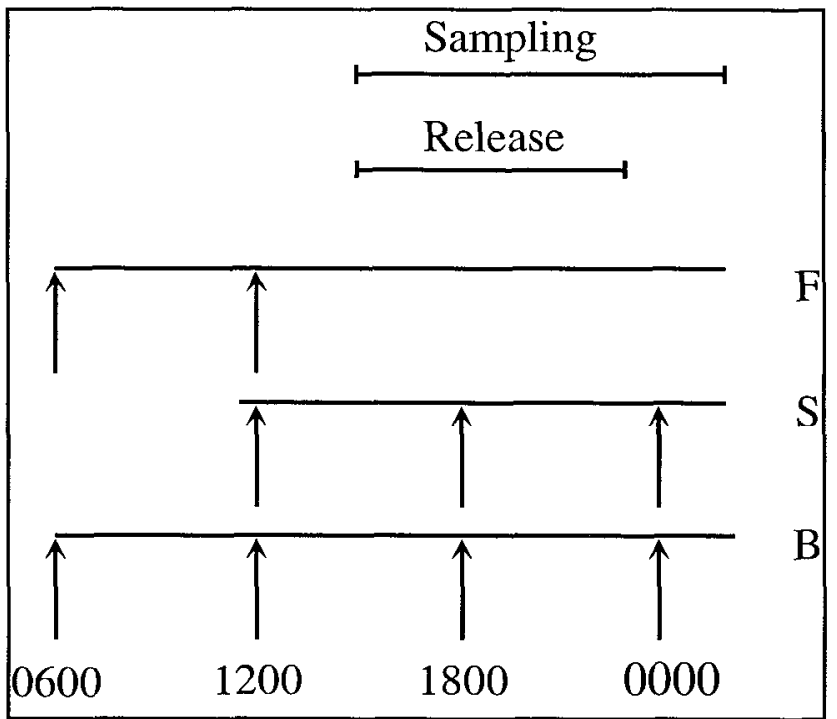

Figure 6. Time lines for COAMPS runs, $\mathrm{B}$ is the baseline run, $\mathrm{S}$ is cold start at 12:00 UTC, and F is the forecast run. Arrows indicate times for updates with global data. Release and sampling periods are also shown.

incremental update the COAMPS 6-hour

forecast is used as the first guess and the global data provides "pseudo radiosondes" as

observations. MVOI analysis is performed on the global data pressure levels, and the increments, interpolated to the COAMPS sigma levels, are added to the previous 6-hour forecast values. Thus the full integration cycle consists of a "cold start" at 06 UTC, 6-hour COAMPS forecasts, and incremental update cycles at 6-hour intervals, $i . e .$, at 12,18 and 00 UTC. The complete run starts at 06 UTC and stops at 02 UTC the next day at the end of the tracer sampling period. This is shown by time line B in Figure 6.

Besides the base simulation described in the previous paragraph, we performed a couple of modified simulations. First, we ran a test to investigate whether a 3-hour spin up time would be sufficient, and second, we did a simulated emergency response simulation. In the investigation to test the necessary spin up time, we ran cases that started at 12 UTC rather than at 06 UTC. This 
is shown by the $\mathrm{S}$ time line in Figure 6 . For the emergency response simulation we assumed the last global data available was at 12 UTC. We used the first 12 hours of the baseline simulation, a "cold start" at 06 UTC and an update cycle at 12 UTC, but then we did not perform update cycles at 18 or 00 UTC. Therefore, the final 14 hours of the simulation, including the entire release period, is purely a COAMPS forecast. The forecast experiment is time line F in Figure 6.

\section{Meteorological Conditions}

We performed COAMPS/LODI simulations of the tracer releases for the first three DOPPTEX experiment days, August 31, September 2, and September 4, 1986. We chose these days because they represent a range of large-scale meteorological conditions.

\section{A. August 31, 1986 - Strong synoptic forcing}

On August 31, 1986, the south-central California coast was under the influence of a region of high pressure in the eastern Pacific. With a moderately strong large-scale pressure gradient, the local winds were strongly influenced by the north northwest synoptic flow that was nearly parallel to the coastline. Plots of the ECMWF reanalysis surface pressure and $700 \mathrm{mb}$ height fields for 18 UTC on August 31, 1986 are shown in Figures 7 and 8.

An important aspect of the low level meteorology along the California coast in summer is the thermal stability. A persistent inversion exists at the top of the marine layer associated with subsidence on the eastern side of the high pressure region. Temperature and potential temperature soundings from the reanalysis data at $35 \mathrm{~N}, 120 \mathrm{~W}$, the grid-point closest to Diablo Canyon (about $80 \mathrm{~km} \mathrm{ESE),} \mathrm{are} \mathrm{given} \mathrm{in} \mathrm{Figures} 9$ and 10. The vertical resolution of the ECMWF 


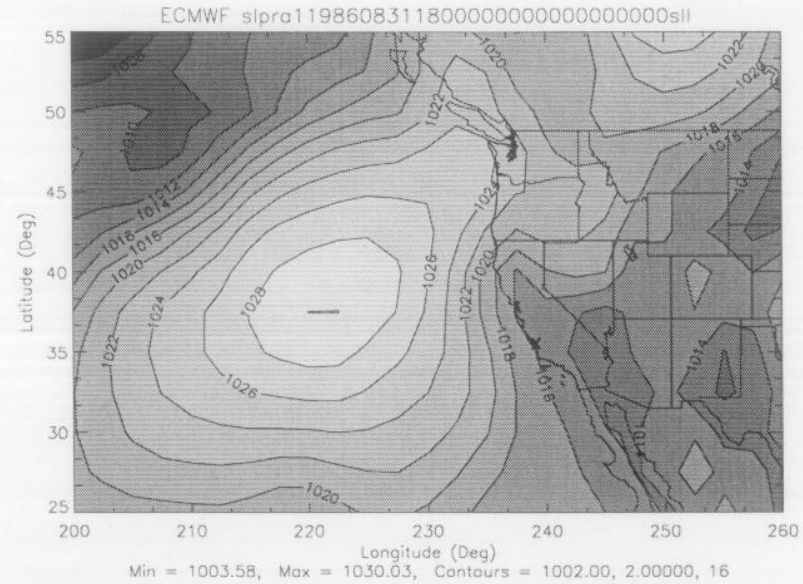

Figure 7. Surface Pressure from ECMWF reanalysis for 18 UTC on August 31, 1986.

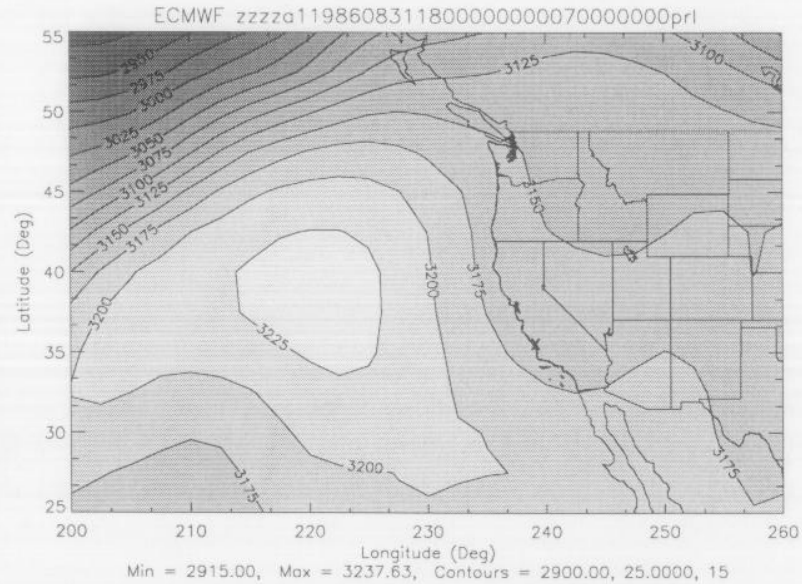

Figure $8.700 \mathrm{mb}$ heights form ECMWF reanalysis for 18 UTC on August 31, 1986.

reanalysis data is often too low to differentiate the inversion layer, and that is one weakness of these simulations. The purpose of the spin up is to enable the model to define this inversion and to permit the winds to adjust to the local topography.

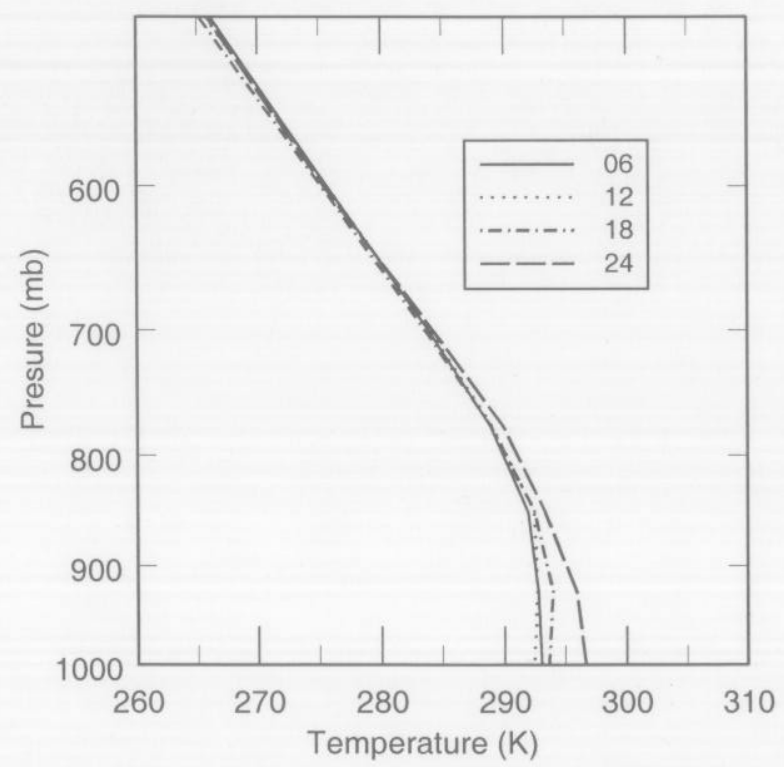

Figure 9. Temperature sounding from ECMWF Figure 10. Potential temperature from ECMWF reanalysis for $06,12,18$, and $24 \mathrm{UTC}$ on August 31,1986 at $35 \mathrm{~N}, 120 \mathrm{~W}$.

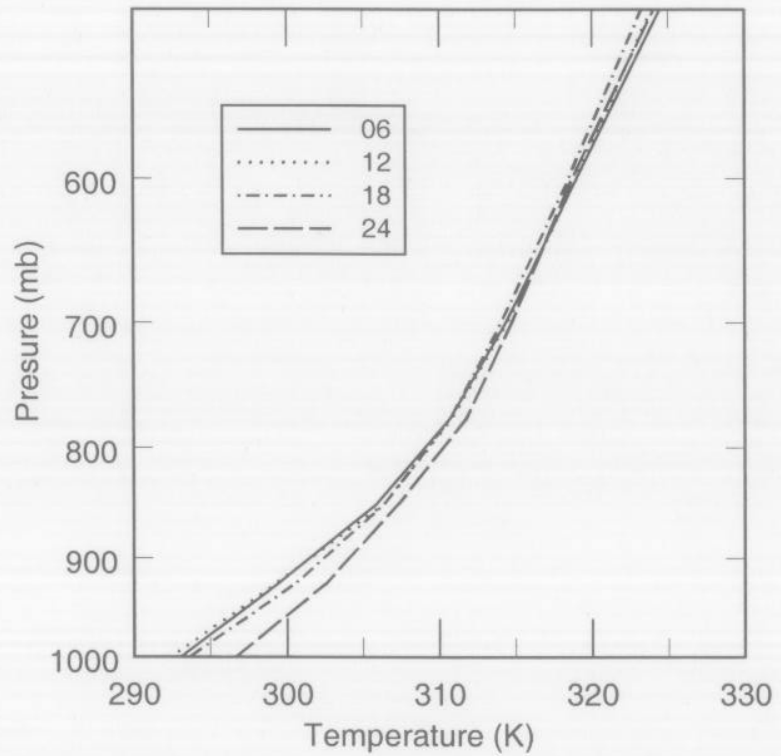

reanalysis for $06,12,18$, and 24 UTC on August 31, 1986 at $35 \mathrm{~N}, 120 \mathrm{~W}$. 


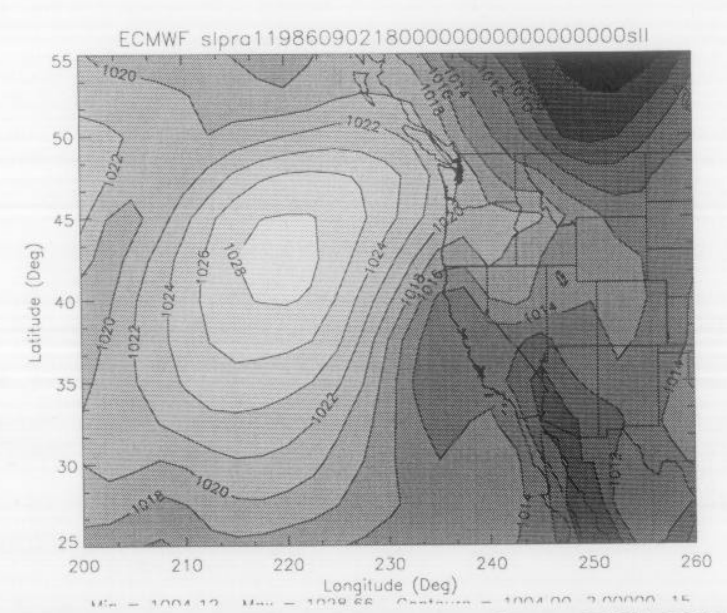

Figure 11. Surface Pressure from ECMWF reanalysis for 18 UTC on September 2, 1986.

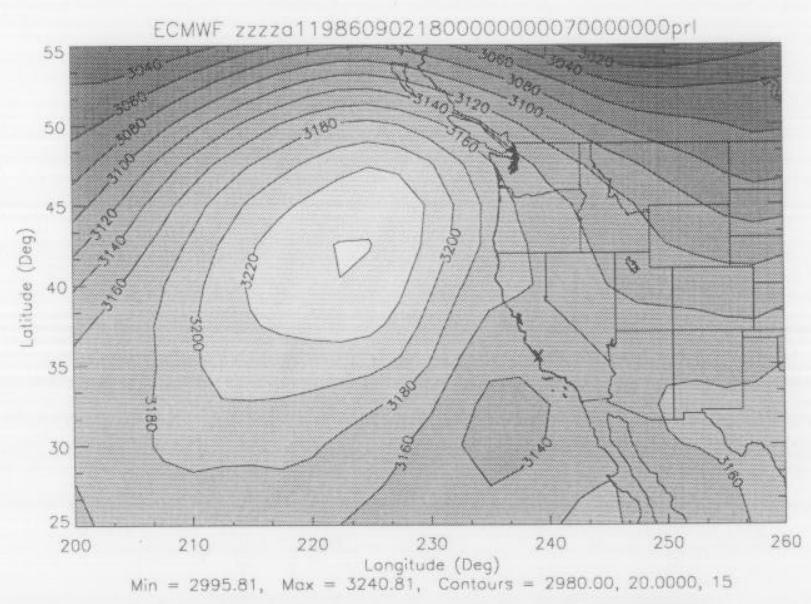

Figure 12. $700 \mathrm{mb}$ heights form ECMWF reanalysis for 18 UTC on September 2, 1986.

\section{B. September 2, 1986 - Weak southerly synoptic forcing}

By September 2, 1986, the western Pacific high pressure region has weakened a bit and drifted to the north, and the thermal low over the gulf of California has extended across the south-central coast region and Diablo Canyon. At $700 \mathrm{mb}$ a small low pressure center is found to

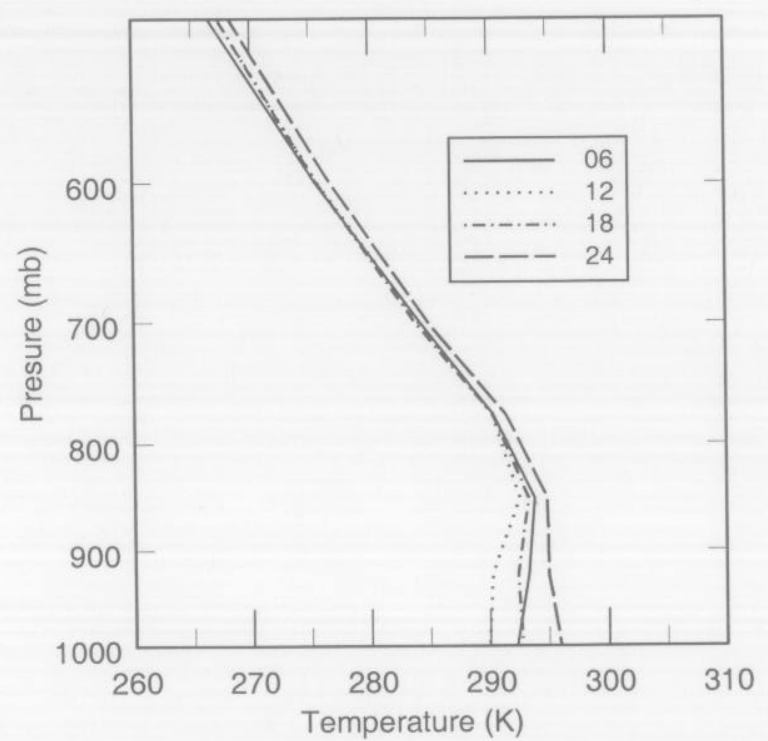

Figure 13. Temperature sounding from ECMWF reanalysis for $06,12,18$, and 24 UTC on September 2, 1986 at 35 N, 120 W.

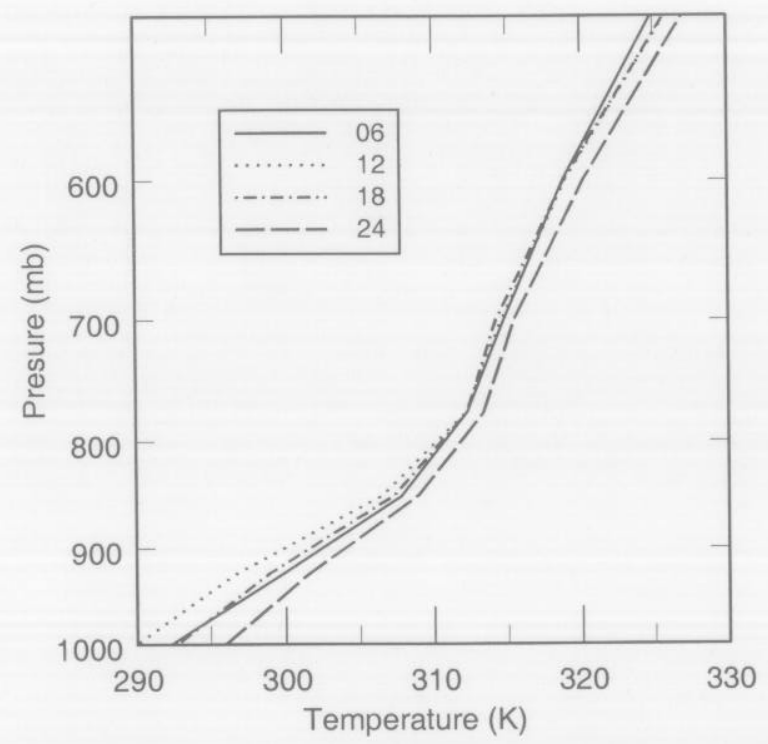

Figure 14. Potential temperature from ECMWF reanalysis for $06,12,18$, and 24 UTC on August 31, 1986 at 35 N, 120 W. 
the southwest of Diablo Canyon. In the morning the synoptic flow is weak southerly and during the day weakens even more and turns southeasterly. Some of these features are shown by the sea level pressure and $700 \mathrm{mb}$ height plots from ECMWF reanalysis in Figures 11 and 12.

The large scale thermal structure of the atmosphere is shown by the temperature and potential temperature soundings at the global data point closest to Diablo Canyon in Figures 13 and 14. The lower part of the atmosphere is quite stable as manifest by the nearly isothermal region or slight inversion that persisted throughout the day below about $800 \mathrm{mb}$.

\section{September 4, 1986 - Weak northerly synoptic forcing}

On September 4, 1986, the sea-level pressure gradient in the Diablo Canyon area goes from higher pressure centered off the coast of San Diego to lower pressure centered in the Gulf of California. This produces weak northerly flow near the surface. At $700 \mathrm{mb}$ there is almost no pressure gradient as Diablo Canyon is situated on an axis of high pressure running from off the coast near the California-Oregon border to the desert southwest. These features are shown in the sea level pressure and $700 \mathrm{mb}$ height plots from ECMWF reanalysis in Figures 15 and 16.

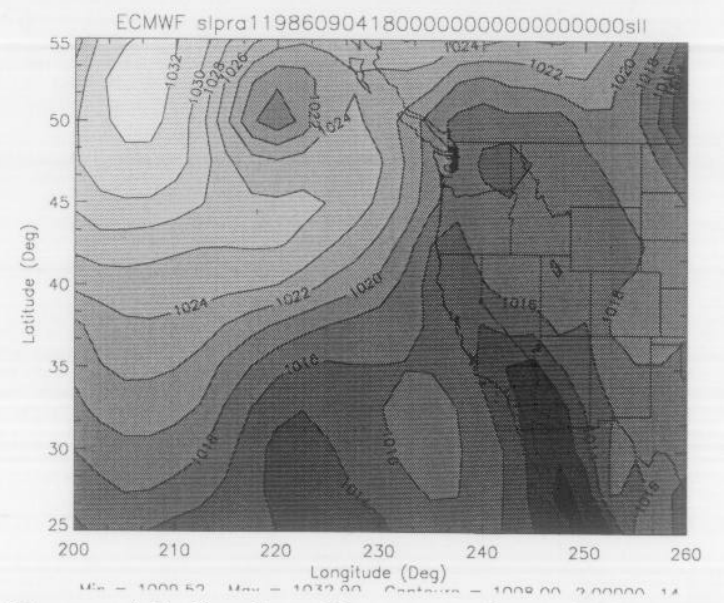

Figure 15. Surface Pressure from ECMWF reanalysis for 18 UTC on September 4, 1986.

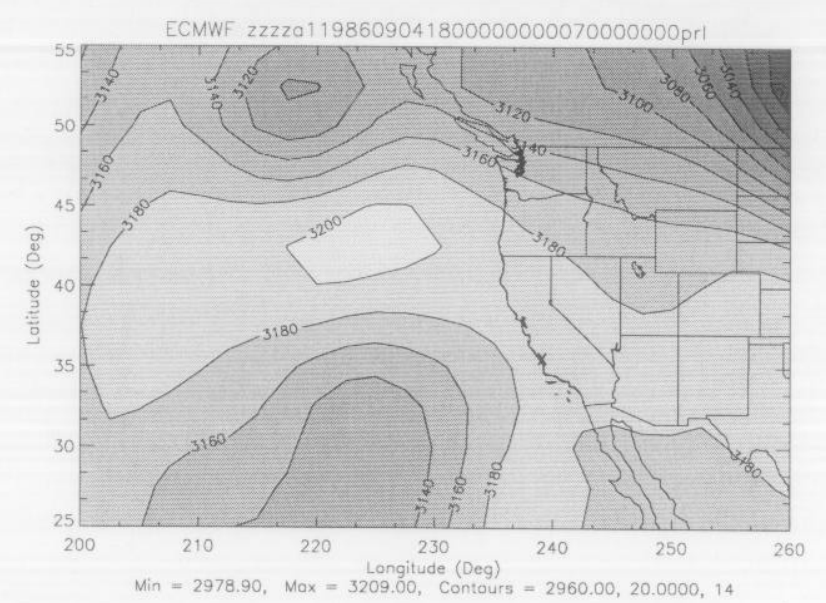

Figure 16. $700 \mathrm{mb}$ heights form ECMWF reanalysis for 18 UTC on September 4, 1986. 


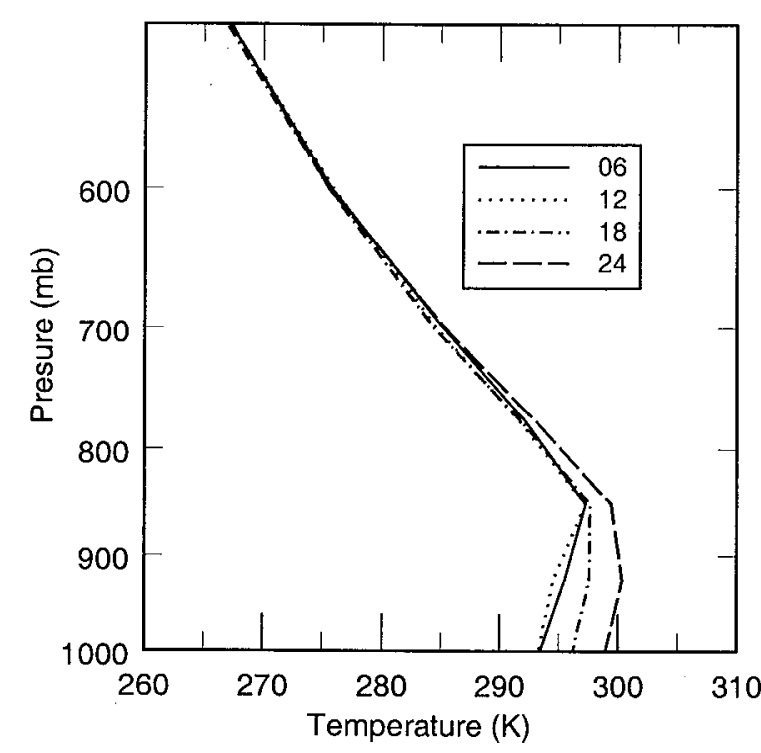

Figure 17. Temperature sounding from ECMWF reanalysis for $06,12,18$, and 24 UTC on September 4, 1986 at 35 N, 120 W.

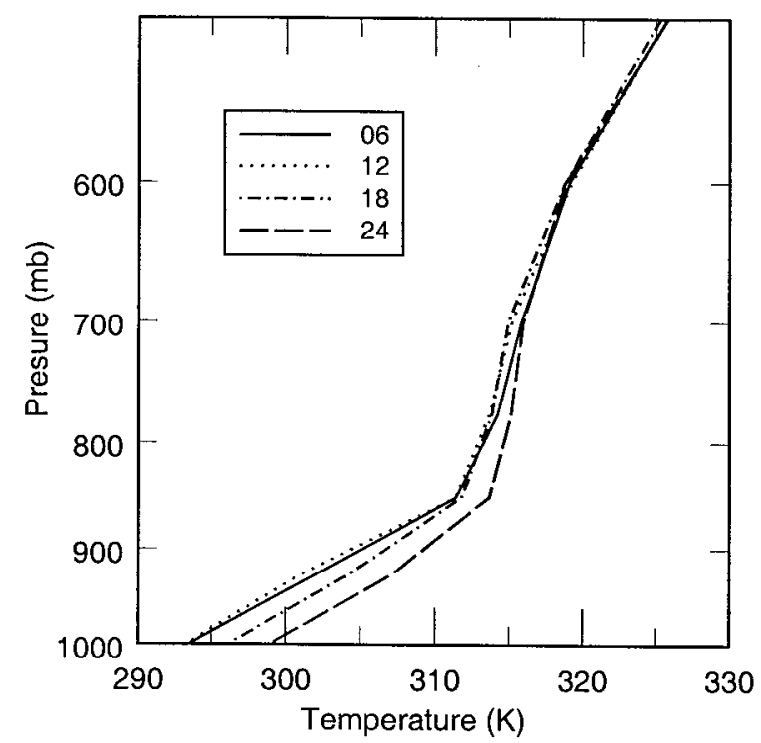

Figure 18. Potential temperature from ECMWF reanalysis for $06,12,18$, and 24 UTC on September 4, 1986 at 35 N, $120 \mathrm{~W}$.

Again strong thermal stability exists in the lower atmosphere on September 4, 1986 as shown by the temperature and potential temperature soundings for the global data point closest to Diablo Canyon in Figures 17 and 18. The part of the atmosphere near $850 \mathrm{mb}$ is warmer than it was on September 2, with a moderately strong inversion below that level. The stable layer is shallower than on September 2.

\section{Prognostic Simulations}

\section{A. Description of COAMPS Simulation Procedure}

COAMPS simulations for August 31, September 2, and September 4, 1986 were performed independently; each was initiated from the ECMWF reanalysis at 06 UTC on the corresponding day (11pm PDT on the previous day). An incremental update was performed at 12 UTC (5am PDT). For the base run (B in Figure 6) COAMPS was integrated for 6-hour periods with incremental updates performed at 18 UTC (11am PDT) and 00 UTC (5pm PDT) using the 
ECMWF reanalysis data as pseudo soundings. The base run ended at 02 UTC the following day (7pm PDT) when tracer sampling stopped. For the forecast run (F in Figure 6) COAMPS was integrated for 14 hours after the incremental update at 12 UTC until 02 UTC the following day (7pm PDT) when tracer collection at the sampling sites concluded.

COAMPS's nests are those described in Section III.B.3 (pg.10). Topography data is from a 1 $\mathrm{km}$ resolution global data set; it was smoothed to eliminate $2 \Delta \mathrm{x}$ oscillations. All of COAMPS's physical processes were active. Although clouds formed over the ocean, primarily during the night, no clouds were present over the Diablo Canyon area during the tracer experiments. With the $1 \mathrm{~km}$ resolution (627595 total grid points and $3 \mathrm{sec}$ inner nest time step), COAMPS required $12 \mathrm{CPU}$ minutes on a $625-\mathrm{MHz}$ DEC alpha processor to simulate each minute of real time; a 14 hour simulation took about 168 hours (7 days) of CPU time.

The primary output from COAMPS in this study is the three-dimensional wind field used by LODI to simulate tracer transport and diffusion. COAMPS's inner nest wind fields were saved every 12 minutes during the tracer release and sampling period from 15 UTC (8am PDT) to 02 UTC the next day (7pm PDT). Note that the entire procedure for initializing, updating, and running COAMPS is based solely on ECMWF global reanalysis data; no local meteorological measurements were used.

\section{B. Description of LODI Procedure}

LODI was used to predict tracer concentrations based on COAMPS's wind fields. Source release rates and locations are given in Table 1 (pg. 6). The initial dispersion of the tracer and the diffusion properties of the atmosphere were specified based on observations in the area at the 


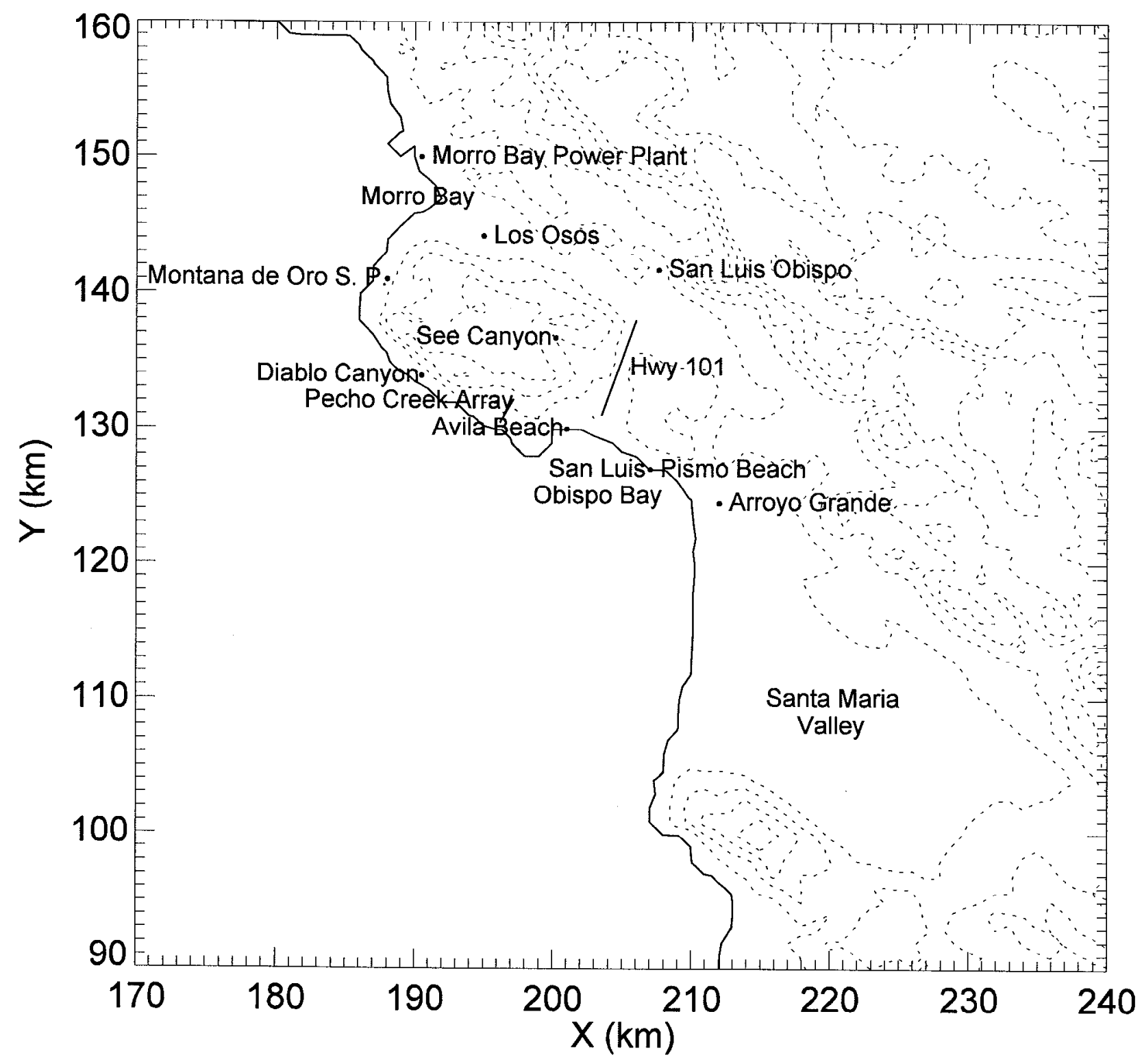

Figure 19. Names of places in the Dopptex experiment area.

time of the release (Nasstrom, personal communication). We did not use diffusion parameters from CO $\Lambda$ MPS in this simulation, although that data is available.

\section{Predicted Concentrations and Comparison to Tracer Samples}

In the following sections we describe results for each of the three experimental days. Placenames used in the discussion of results are given on the map in Figure 19. 


\section{August 31, 1986}

The synoptic flow near Diablo Canyon on August 31, 1986 was moderate from the northwest and quite consistent throughout the day. $\mathrm{SF}_{6}$ was released during three 2 -hour periods from the Diablo Canyon Power Plant.

\section{a. Baseline Simulation}

Figure 20 shows the hourly average $\mathrm{SF}_{6}$ concentrations for both the samplers and the baseline COAMPS/LODI simulation from 16 UTC to 02 UTC (9am to 7pm PDT) on August 31, 1986. In these plots the model concentrations are shown by the shaded contours with magnitudes in $\mathrm{ng} / \mathrm{m}^{3}$ as given by the legend at the top right. Dotted contours are the model topography at $100 \mathrm{~m}$ intervals. The tracer release point at Diablo Canyon is indicated by the + symbol. The measured hourly average concentrations are represented by symbols at each sampler site. Measured concentrations below the background value of $50 \mathrm{ng} / \mathrm{m}^{3}$ are represented by small black circles. Above-background measured concentrations are indicated by the sequence of progressively larger triangles, squares, diamonds, and circles. The size of the symbol is proportional to the logarithm of the measured concentration according to the ranges given in the legend at the bottom right of each plot. The $\mathrm{X}$ and $\mathrm{Y}$ coordinates are $\mathrm{km}$ from an arhitrary origin.

Simulated transport of $\mathrm{SF}_{6}$ from the first release, 15-17 UTC (8-10am PDT), is quite rapid to the southwest along the coast, over San Luis Obispo Bay and into the Santa Maria Valley. Compared with the observed $\mathrm{SF}_{6}$ concentrations the southwest transport by the model is clearly too fast. The model plume reached Arroyo Grande by 17 UTC (10am PDT) while the first observational evidence for $\mathrm{SF}_{6}$ in this area does not occur until 19 UTC (12pm PDT), two hours later. Transport of part of this release into and through the Santa Maria Valley is supported by 



Figure 20. Hourly average $\mathrm{SF}_{6}$ concentration $\left(\mathrm{ng} / \mathrm{m}^{3}\right)$ at 16-18 UTC (9-11 am PDT) for the August 31, 1986 release from Diablo Canyon. Shaded contours are calculated concentrations; symbols represent measured concentrations. Dotted contours are topography in $100 \mathrm{~m}$ intervals; + indicates the release point. $\mathrm{SF}_{6}$ was relcased from 15-17 and 21-23 UTC (8-10 am and 2-4 pm PDT) at $71 \mathrm{~m}$ and from 18-20 UTC (11 am-1 pm PDT) at $1.5 \mathrm{~m}$. 

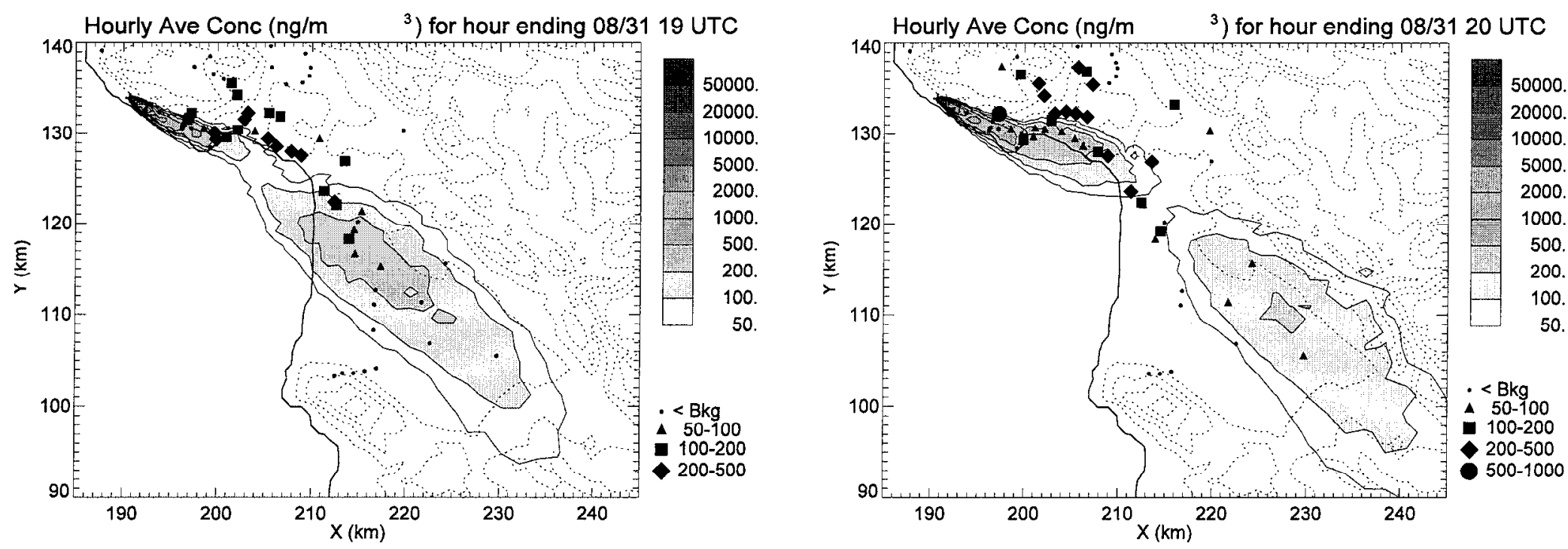

$\underline{N}$
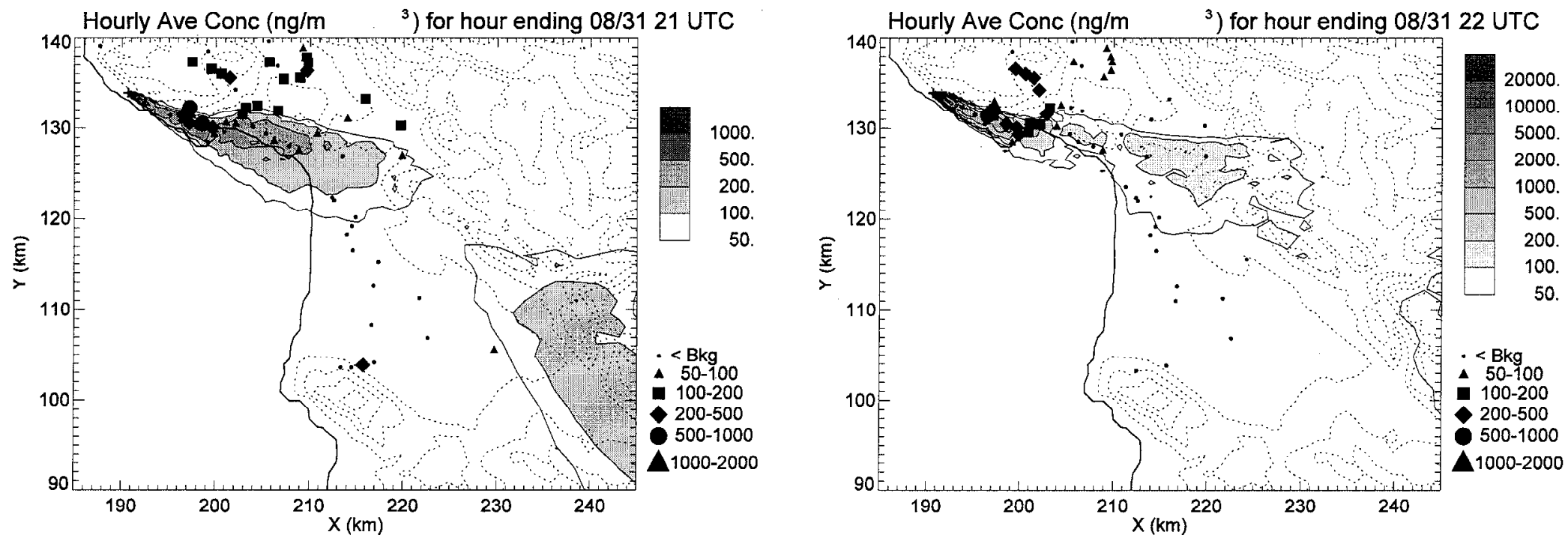

Figure 20 (continued). Hourly average $\mathrm{SF}_{6}$ concentration $\left(\mathrm{ng} / \mathrm{m}^{3}\right)$ at $19-22 \mathrm{UTC}(12-3 \mathrm{pm})$ for the August 31,1986 release from Diablo Canyon. Shaded contours are calculated concentrations from the baseline run with global updates at 18 and 22 UTC; symbols represent measured concentrations. Dotted contours are topography in $100 \mathrm{~m}$ intervals; + indicates the release point. $\mathrm{SF}_{6} \mathrm{was}_{\mathrm{seleased}}$ from 15-17 and 21-23 UTC (8-10 am and 2-4 pm PDT) at $71 \mathrm{~m}$ and from 18-20 UTC (11 am-1 pm PDT) at $1.5 \mathrm{~m}$. 

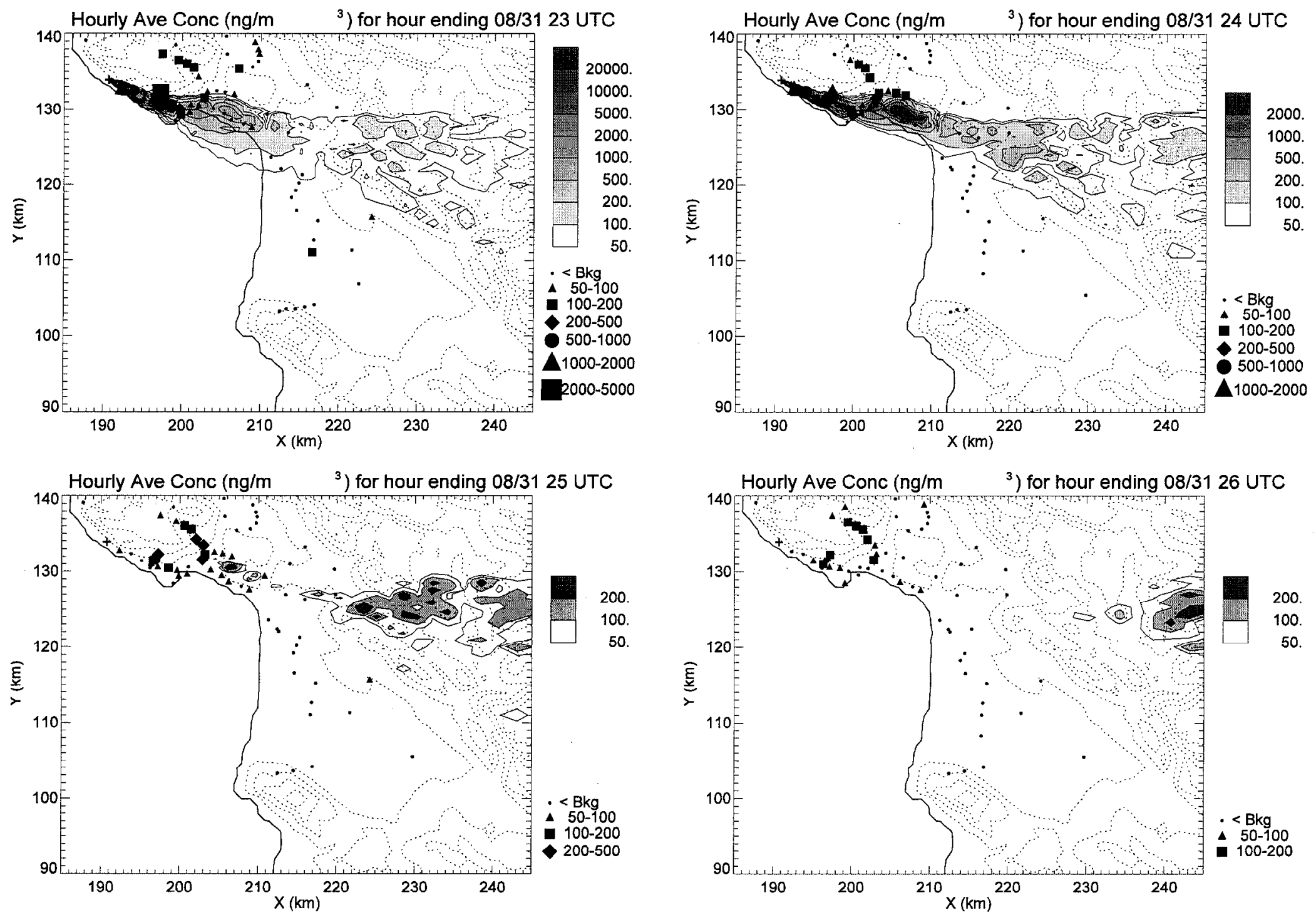

Figure 20 (continued). Hourly average $\mathrm{SF}_{6}$ concentration $\left(\mathrm{ng} / \mathrm{m}^{3}\right)$ at 23-26 UTC (4-7 pm) for the August 31 , 1986 release from Diablo Canyon. Shaded contours are calculated concentrations from the baseline run with global updates at 18 and 24 UTC; symbols represent measured concentrations. Dotted contours are topography in $100 \mathrm{~m}$ intervals; + indicates the release point. $\mathrm{SF}_{6}$ was released from 15-17 and 21-23 UTC (8-10 am and 2-4 pm PDT) at $71 \mathrm{~m}$ and from 18-20 UTC (11 am-1 pm PDT) at $1.5 \mathrm{~m}$. 
observations at 20 and 21 UTC ( 1 and 2pm PDT). The observations also suggest that some $\mathrm{SF}_{6}$ from this release follows the coastline to Avila Beach, then moves north along the highway 101 alignment toward San Luis Obispo and finally turns northwest and collects in See Canyon. The simulation completely misses this part of the plume. This failure is partly a result of the too rapid transport of $\mathrm{SF}_{6}$ to the southwest by COAMPS's wind fields and partly because COAMPS develops the northerly flow along the highway 101 alignment too slowly and with too small a magnitude. Possibly COAMPS underestimates surface heating or overestimates surface wetness, thereby under predicting the diurnal range of near-surface air temperature. As a consequence, development of the sea breeze inland toward San Luis Obispo is delayed and limited. Also, See Canyon is a terrain feature that is not well
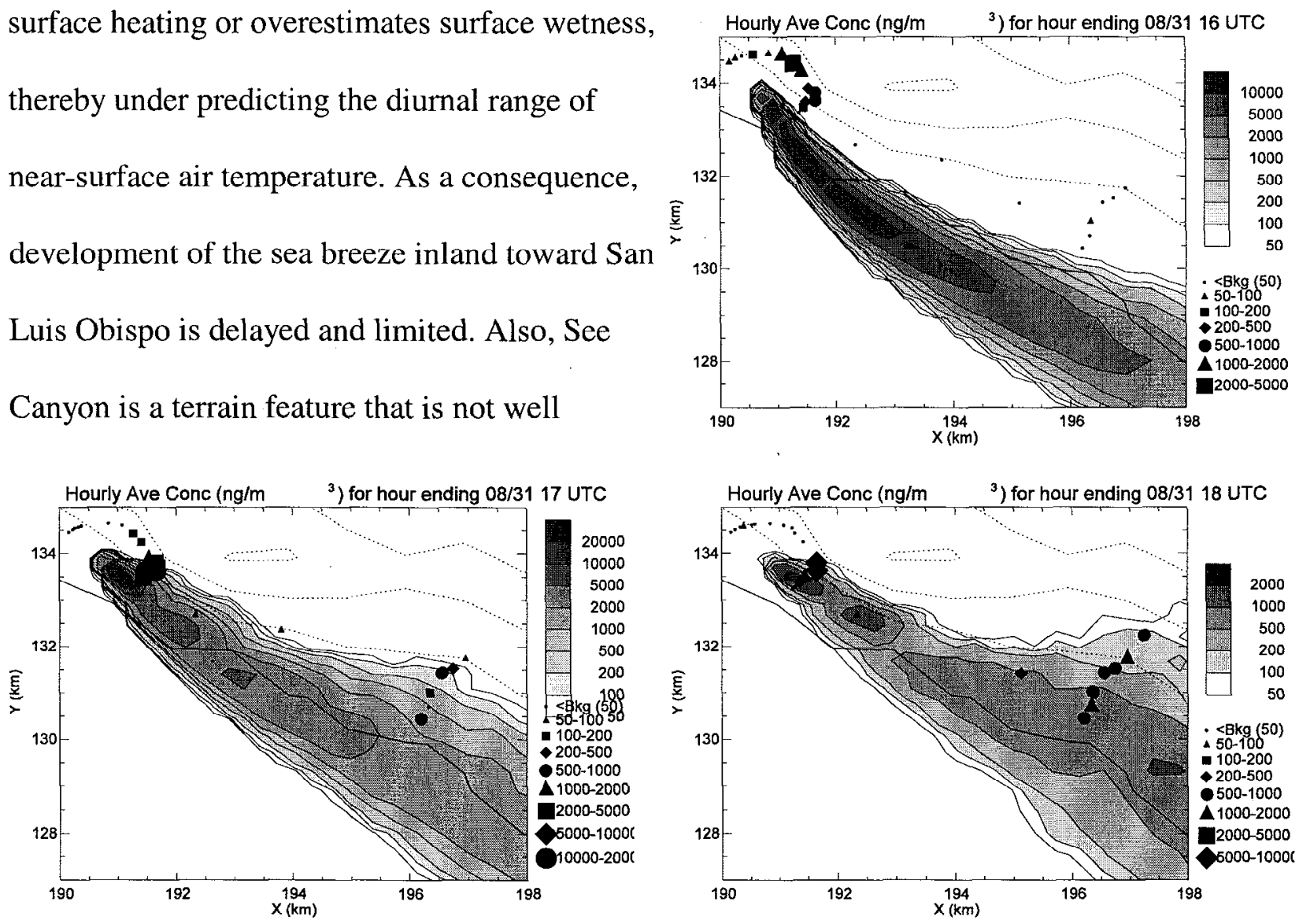

Figure 21. Hourly average $\mathrm{SF}_{6}$ concentration $\left(\mathrm{ng} / \mathrm{m}^{3}\right)$ at 9,10 and 11 am $(16,17$ and $18 \mathrm{UTC})$ for the August 31, 1986 release from Diablo Canyon showing the close in samplers. Shaded contours are calculated concentrations; symbols are corresponding measured concentrations. + indicates the release point. $\mathrm{SF}_{6}$ was released from 8-10 am and from $2-4 \mathrm{pm}$ at $71 \mathrm{~m}$ and from $11 \mathrm{am}-1 \mathrm{pm}$ at $1.5 \mathrm{~m}$. 

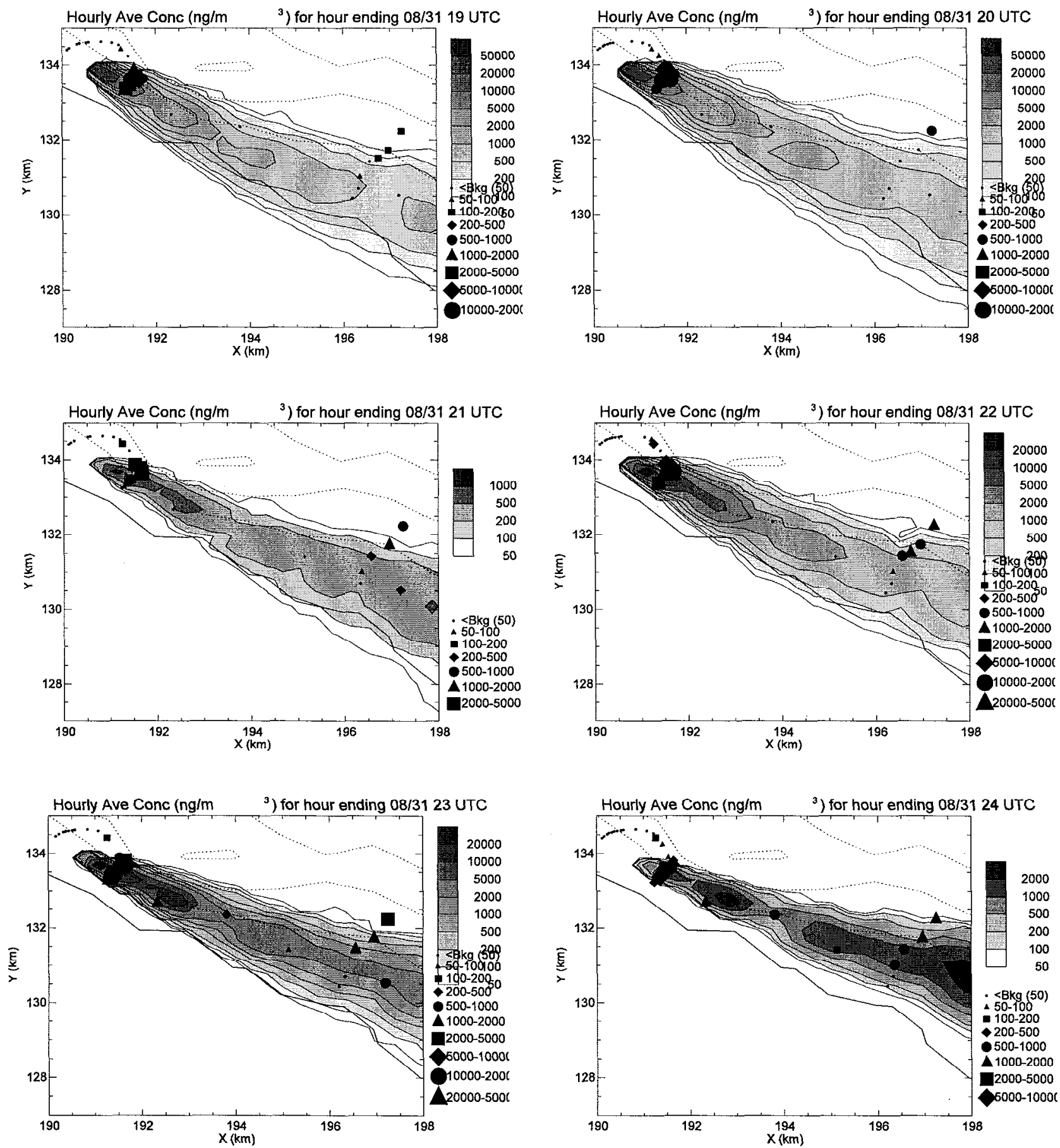

Figure 21 continued. Hourly average $\mathrm{SF}_{6}$ concentrations $\left(\mathrm{ng} / \mathrm{m}^{3}\right)$ from 19-24 UTC (12-5 pm PDT) for the August 31, 1986 release from Diablo Canyon showing the close-in samplers. Shaded contours are calculated concentrations for the baseline run; symbols represent measured concentrations. + indicates the release point. $\mathrm{SF}_{6}$ was released from 15-17 and 21-23 UTC (8-10 am and 2-4 pm PDT) at $71 \mathrm{~m}$ and from 18-20 UTC (11 am-1 pm) at the $1.5 \mathrm{~m}$. 
resolved by the $1 \mathrm{~km}$ grid spacing of COAMPS's inner nest.

Details of the transport of $\mathrm{SF}_{6}$ close to Diablo Canyon are provided in Figure 21; it shows the modeled plume and measured concentrations from an arc of samplers about $1 / 2$ mile $(850 \mathrm{~m})$ from the release point. These plots indicate that tracer from the morning release probably drifted upslope and remained near the power plant for an hour or more instead of being rapidly transported to the southwest.

For the two later releases of $\mathrm{SF}_{6}$ on August 31, the model plume moves slightly inland of the coastline and parallel to it. Observations suggest that the plume actually moved more easterly and stayed to the north of most of the sensors, affecting mostly the northern ones in the line near Pecho Creek, $6.5 \mathrm{~km}$ east southeast of Diablo Canyon; the lack of sensors on the slope makes it difficult to conclude that this was the actual tracer trajectory. The persistence of abovebackground concentrations for the samplers in See Canyon would be consistent with transport of material over the hills behind Avila Beach and into See Canyon. Measurements also imply that tracer continued to move up the 101 corridor toward San Luis Obispo with some collecting in See Canyon. However, the model pushes the material to the east of highway 101 where no samplers collected $\mathrm{SF}_{6}$ in above-background concentrations. The model also predicts quite high concentrations of the tracer on the hills behind Pismo Beach. This is nol supported by observations, although the samples were collected at lower elevations right along the coast rather than in the hills.

\section{b. Forecast Simulation}

The results of COAMPS/LODI's forecast simulation for August 31, 1986 are given in Figure 22. Since the baseline simulation's first update cycle is at 18 UTC (11am PDT), the first 

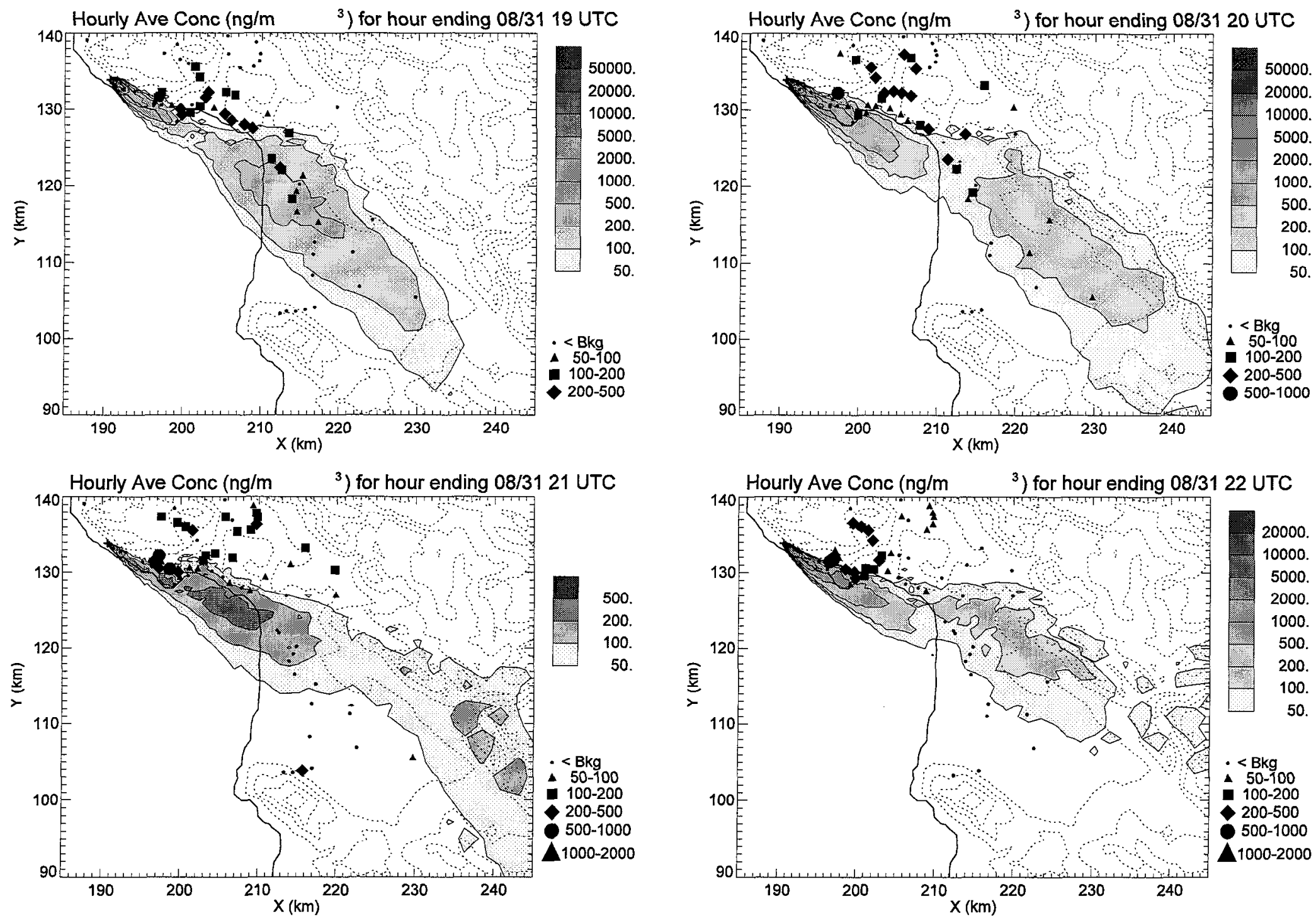

Figure 22. Hourly average $\mathrm{SF}_{6}$ concentration $\left(\mathrm{ng} / \mathrm{m}^{3}\right)$ at 19-22 UTC (12-3 pm PDT) for the August 31,1986 release from Diablo Canyon. Shaded contours are calculated concentrations from the COAMPS forecast run with no global updates; symbols represent measured concentrations. Dotted contours are topography in $100 \mathrm{~m}$ intervals; + indicates the release point. $\mathrm{SF}_{6}$ was released from 15-17 and 21-23 UTC (8-10 am and 2-4 pm PDT) at $71 \mathrm{~m}$ and from 18-20 UTC (11 am-1 pm PDT) at $1.5 \mathrm{~m}$. 

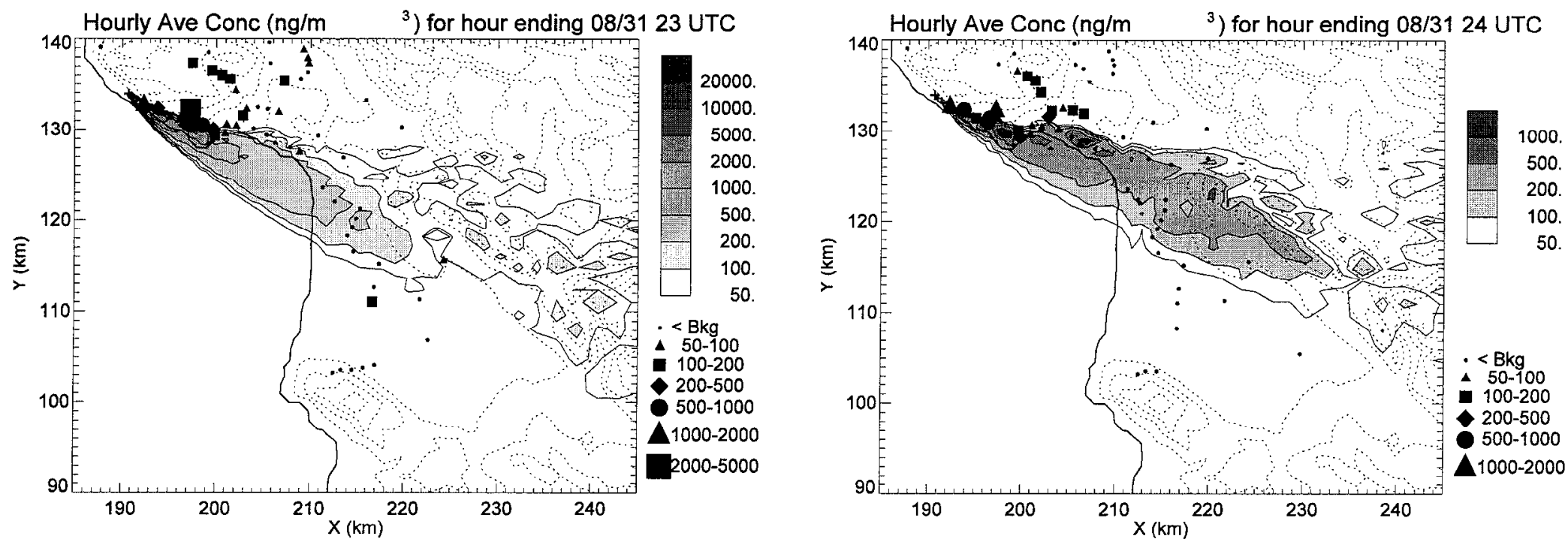

N
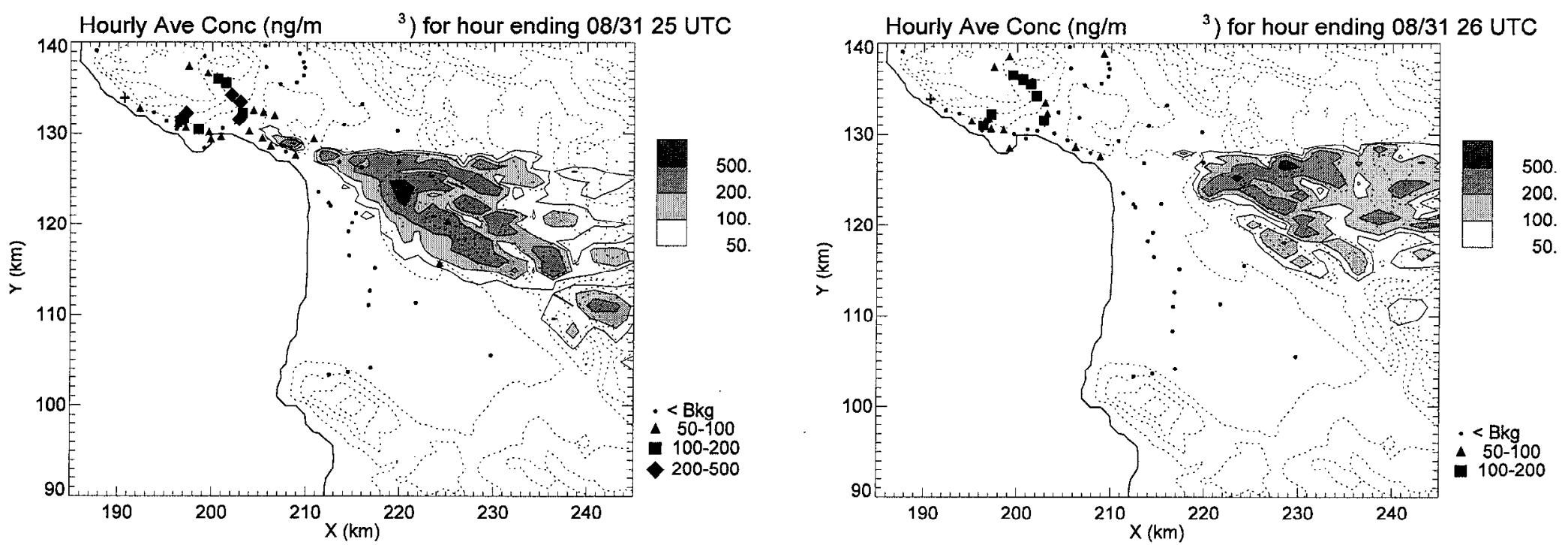

Figure 22 (continued). Hourly average $\mathrm{SF}_{6}$ concentration $\left(\mathrm{ng} / \mathrm{m}^{3}\right)$ at 23-26 UTC (4-7 pm) for the August 31, 1986 release from Diablo Canyon. Shaded contours are calculated concentrations from the forecast run with no global updates; symbols represent measured concentrations. Dotted contours are topography in $100 \mathrm{~m}$ intervals; + indicates the release point. $\mathrm{SF}_{6}$ was released from $15-17$ and 21-23 UTC (8-10 am and 2-4 pm PDT) at $71 \mathrm{~m}$ and from 18-20 UTC (11 am-1 pm PDT) at $1.5 \mathrm{~m}$. 
time the hourly average concentration plots can differ is for the hour ending at 19 UTC (12pm PDT). The primary difference in these simulations is that the winds for the forecast run have a more northerly component that does not permit tracer transport northward through the 101 corridor toward San Luis Obispo and into See Canyon. This can be clearly seen in Figure 23 which shows the measured concentrations from the close-in arc and the predicted plume from the forecast simulation. At 22 and 23 UTC ( 3 and 4pm PDT) the centerline of the plume from the third release is clearly south of the samplers with high concentrations. The high tracer concentrations predicted by this simulation near Arroyo Grande are also not consistent with the observations. For August 31 the forecast simulation is clearly inferior to the baseline simulation.

The COAMPS/LODI simulation of the August 31, 1986 tracer experiment is only marginally correct. On the positive side, the plume moves in the correct general direction and the hourly average concentrations are of the proper size. This is quite impressive considering that absolutely no local data was used to initialize or update COAMPS. On the negative side, the model predicted flow and dispersion moves the tracer too fast and too far to the east southeast. Predicted winds near the release site are much stronger and more toward the ocean than implied by the measured pollutant concentrations. The model is not successful in predicting the development of a sea breeze and terrain induced flow northward through the 101 corridor toward San Luis Obispo. The tracer samplers in See Canyon also consistently predict high values, but the model does not transport material into this region. Determining how the material was transported into See Canyon is difficult. There are two possibilities: $\mathrm{SF}_{6}$ was transported around the peninsula and up the 101 corridor, or $\mathrm{SF}_{6}$ was transported over the hills and into the canyon. 



Figure 23. Hourly average $\mathrm{SF}_{6}$ concentrations (ng/m $\mathrm{m}^{3}$ ) from 19-24 UTC (12-5 pm PDT) for the August 31, 1986 release from Diablo Canyon showing the close-in samplers. Shaded contours are calculated concentrations from the forecast run; symbols represent measured concentrations. + indicates the release point. $\mathrm{SF}_{6}$ was released from 15-17 and 21-23 UTC (8-10 am and 2-4 pm PDT $)$ at $71 \mathrm{~m}$ and from $18-20$ UTC $(11 \mathrm{am}-1 \mathrm{pm})$ at the $1.5 \mathrm{~m}$. 
In the early part of the day, the former is probably the preferred route, while the latter seems more likely for the second and third releases of $\mathrm{SF}_{6}$.

\section{September 2,1986}

The large-scale forcing on September 2, 1986 was quite weak, much smaller than on August 31,1986 . In the morning the synoptic wind was weak and toward the north; later in the day it acquired a more westerly component. With the weak synoptic forcing, diurnal and terrain induced flows in the region should dominate. $\mathrm{SF}_{6}$ was released during three 2 -hour periods from the Diablo Canyon Power Plant.

a. Baseline Simulation

Figure 24 compares the COAMPS/LODI baseline simulation's hourly average $\mathrm{SF}_{6}$ concentrations with the corresponding measured concentrations from 16 UTC to 02 UTC (9am to 7pm PDT) on September 2, 1986. For the first Diablo Canyon $\mathrm{SF}_{6}$ release, from 15-17 UTC (8-10am PDT), the model predicted plume moves north following the curvature of the coastline but 1-2 km inland. The transport seems to be in the proper direction but a bit too fast. Since there are no hillside sampling sites, deducing the location of the actual plume centerline is impossible, but there is very good agreement between predicted and measured concentrations for the samplers in Montana de Oro State Park, particularly for the hour ending at 18 UTC (1 lam PDT). The COAMPS incremental update cycle at 18 UTC apparently forced the flow in the vicinity of Diablo Canyon to turn toward the west; therefore, the model simulation predicts that most of the $\mathrm{SF}_{6}$ drifted over the ocean west of Morro Bay. While there are no sensors over the ocean to confirm or invalidate this prediction, the samplers between Montana de Oro State Park and Morro Bay indicate that the tracer continued to move north and then east over Morro Bay and 

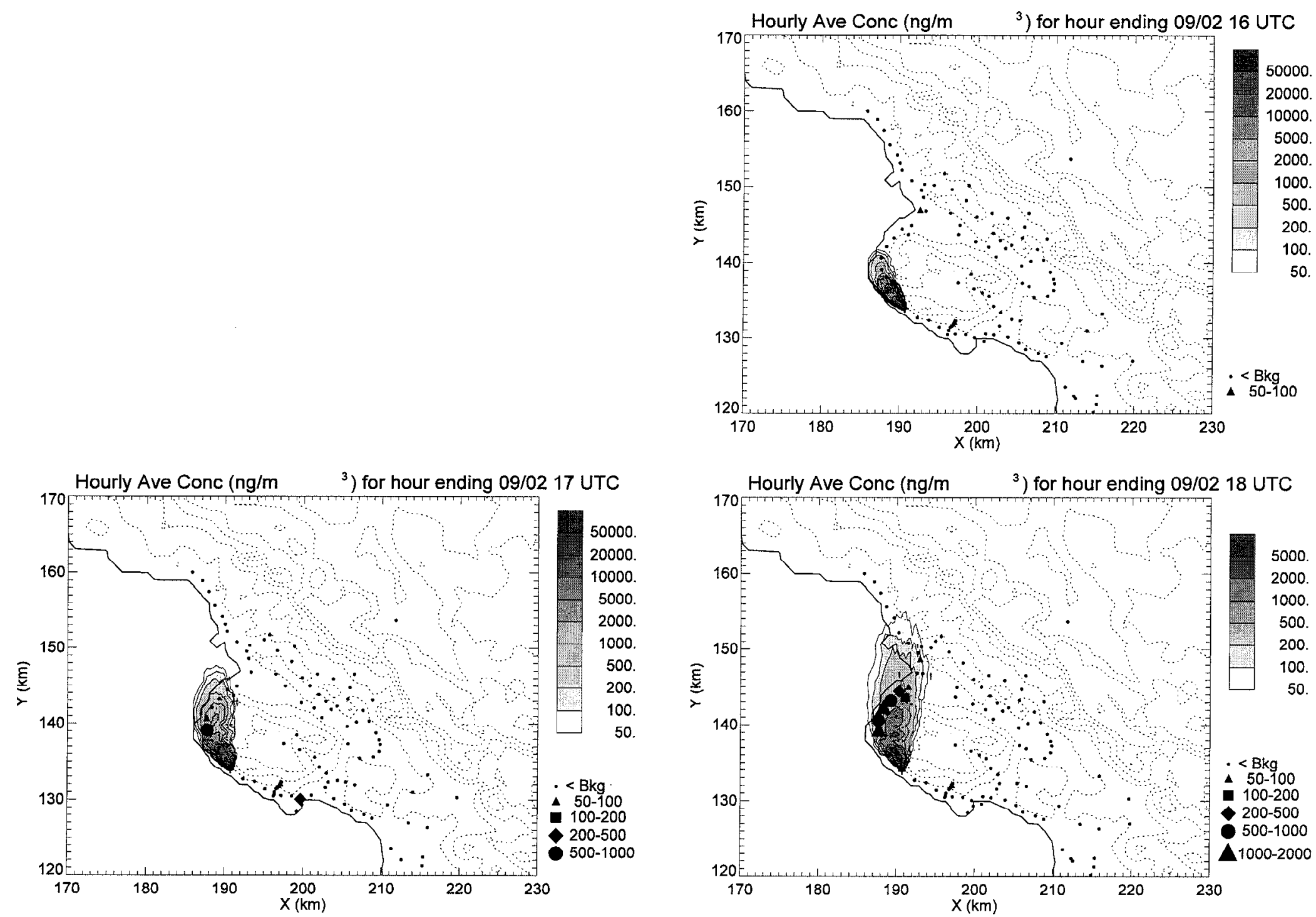

Figure 24. Hourly average $\mathrm{SF}_{6}$ concentration $\left(\mathrm{ng} / \mathrm{m}^{3}\right)$ at 16-18 UTC (9-11 am PDT) for the September 2, 1986 release from Diablo Canyon. Shaded contours are calculated concentrations; symbols are corresponding measured concentrations. Dotted contours are topography in $100 \mathrm{~m}$ intervals; + indicates the release point.SF 6 was relcased from 15-17 and 21-23 UTC (8-10 am and 2-4 pm PDT) at the $1.5 \mathrm{~m}$ and from $20-22$ UTC (11 am-1 pm PDT) at $71 \mathrm{~m}$. 

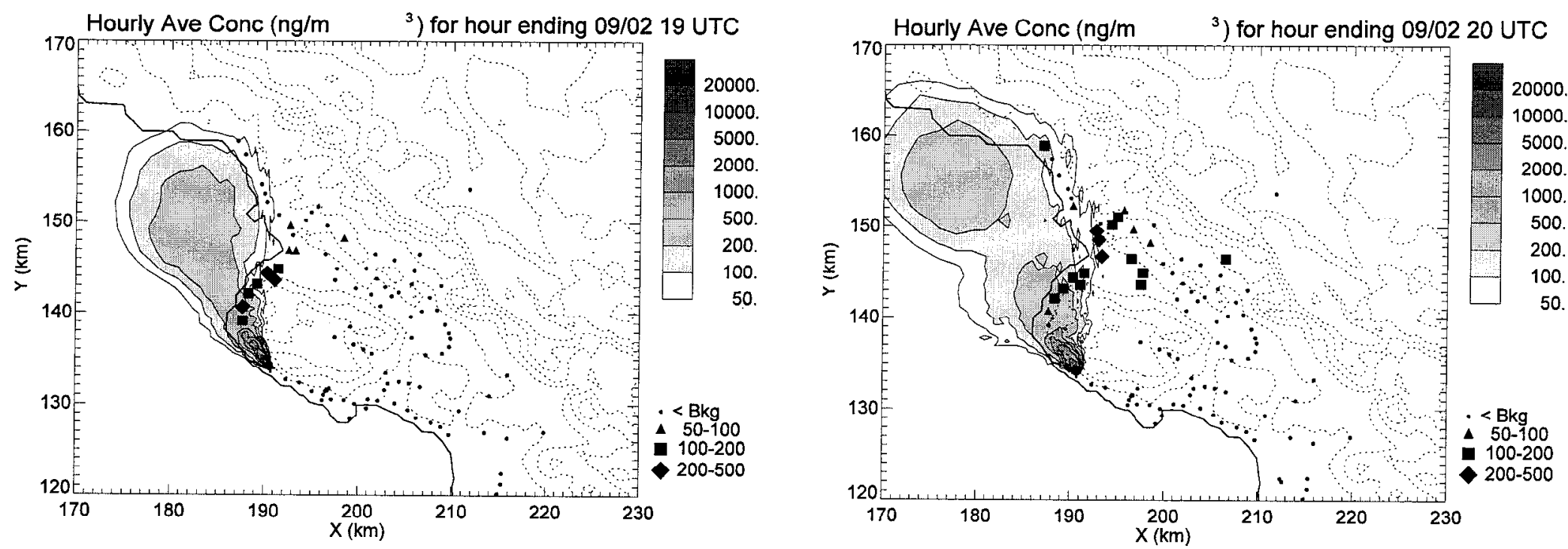

N
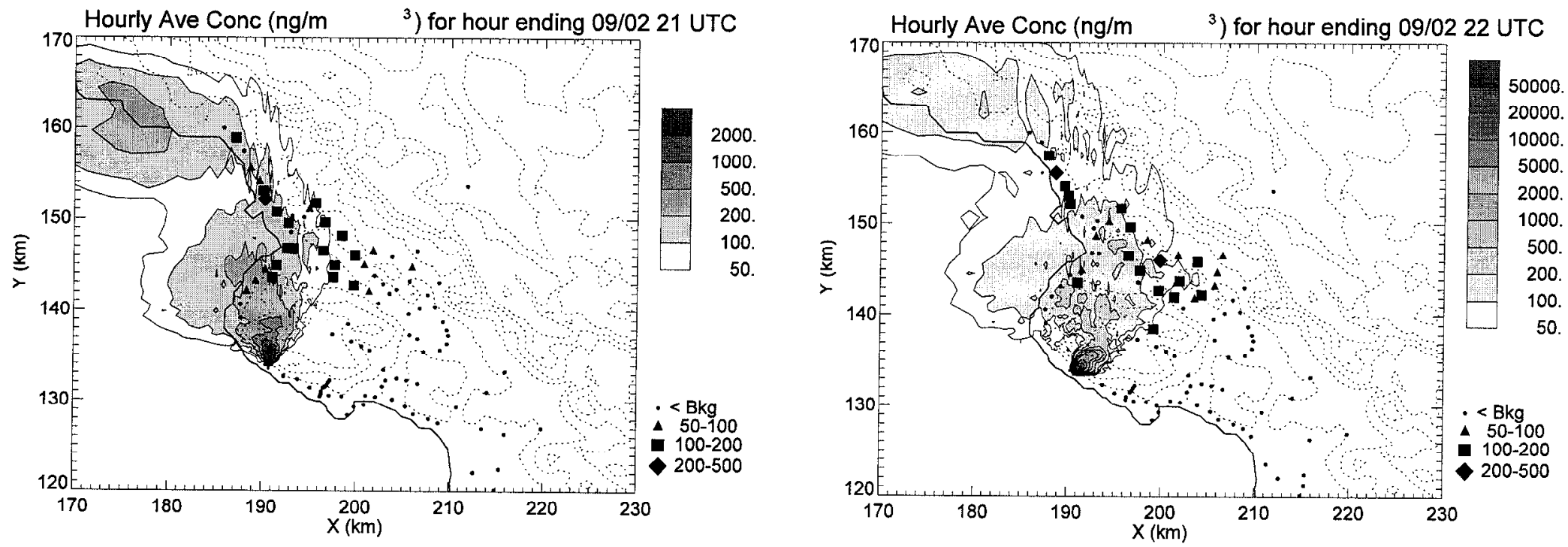

Figure 24 (continued). Hourly average $\mathrm{SF}_{6}$ concentration $\left(\mathrm{ng} / \mathrm{m}^{3}\right)$ at 19-22 UTC (12-3 pm PDT) for the September 2, 1986 release from Diablo Canyon. Shaded contours are calculated concentrations from the baseline run with global updates at 18 and 24 UTC; symbols are corresponding measured concentrations. Dotted contours are topography in $100 \mathrm{~m}$ intervals; + indicates the release point. 

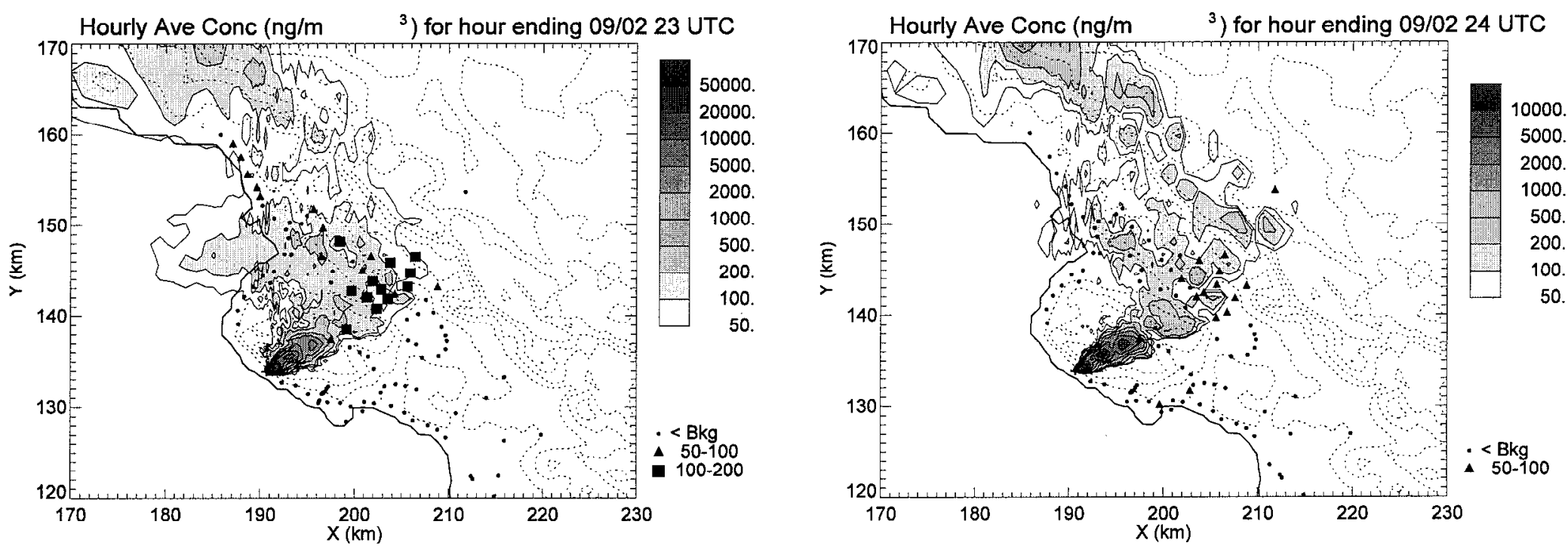

$\stackrel{\omega}{\omega}$


Figure 24 (continued). Hourly average $\mathrm{SF}_{6}$ concentration $\left(\mathrm{ng} / \mathrm{m}^{3}\right)$ at $19-22 \mathrm{UTC}(12-3 \mathrm{pm}$ PDT) for the September 2,1986 release from Diablo Canyon. Shaded contours are calculated concentrations from the baseline run with global updates at 18 and 24 UTC; symbols are corresponding measured concentrations. Dotted contours are topography in $100 \mathrm{~m}$ intervals; + indicates the release point. 
Los Osos. The model predicted drift of this plume from 20 UTC (1pm PDT) until 23 UTC (4pm PDT) is slowly toward the northwest and north until it runs into the coast range at the northern end of the grid. After 22 UTC (3pm PDT) the plume drifts back toward the east until the end of the simulation. There are no samplers over the ocean or in the hills north of Morro Bay to validate or contradict this prediction, but it lacks credibility because the land-based samplers suggest that the plume moved inland rather than over the ocean. On then other hand, elevated observed tracer concentrations just north of the Morro Bay Power Plant from 21-23 UTC (2-4pm $\mathrm{PDT}$ ) is consistent with a plume of $\mathrm{SF}_{6}$ moving over the ocean and then coming back across the coastline with the afternoon sea breeze.

The second $\mathrm{SF}_{6}$ release follows a trajectory similar to the first, north parallel to the coastline but 1-2 km inland. Again the calculated plume spreads over the ocean, although after about 20 UTC (1pm PDT) $\mathrm{SF}_{6}$ does move inland over Morro Bay and Los Osos in very good agreement with the sampler data. The inland penetration is a little too slow; therefore, the highest concentrations in the simulated plume linger along the coast while the observations suggest that $\mathrm{SF}_{6}$ had moved further inland. For example, by 23 UTC (4pm PDT) the observations show the plume is east of Morro Bay and Los Osos, but the model still has concentrations larger than $200 \mathrm{ng} / \mathrm{m}^{3}$ in this area. Also, the simulated plume never gets as far as San Luis Obispo, but some samplers there had $\mathrm{SF}_{6}$ concentrations slightly above background. Nevertheless, for this release the model provides very good agreement with the observations.

Figure 25 provides details of the initial trajectory and dispersion of $\mathrm{SF}_{6}$ within the first few $\mathrm{km}$ of the release point. The model prediction of transport direction, which changes from northwest to east through the day, is excellent. Initial horizontal dispersion of $\mathrm{SF}_{6}$ may be too 
rapid, especially in the afternoon, suggesting that the specified parameters for initial diffusion were too large.

The third $\mathrm{SF}_{6}$ release on September 2, 1986 follows a quite different trajectory in the simulation. It drifts almost directly up the terrain to the east northeast. Since no samplers are in this area, one cannot conclude that this is the correct trajectory. However, the fact that none of the samplers to the northwest or southeast of Diablo Canyon detected $\mathrm{SF}_{6}$ at concentrations above background says the tracer did not go either up or down the coast. Figure 25, which includes observed concentrations for the close-in arc of samplers, shows the simulated plume moving to the east northeast, and this is supported by the measurements. Two samplers located further along the direction of motion of
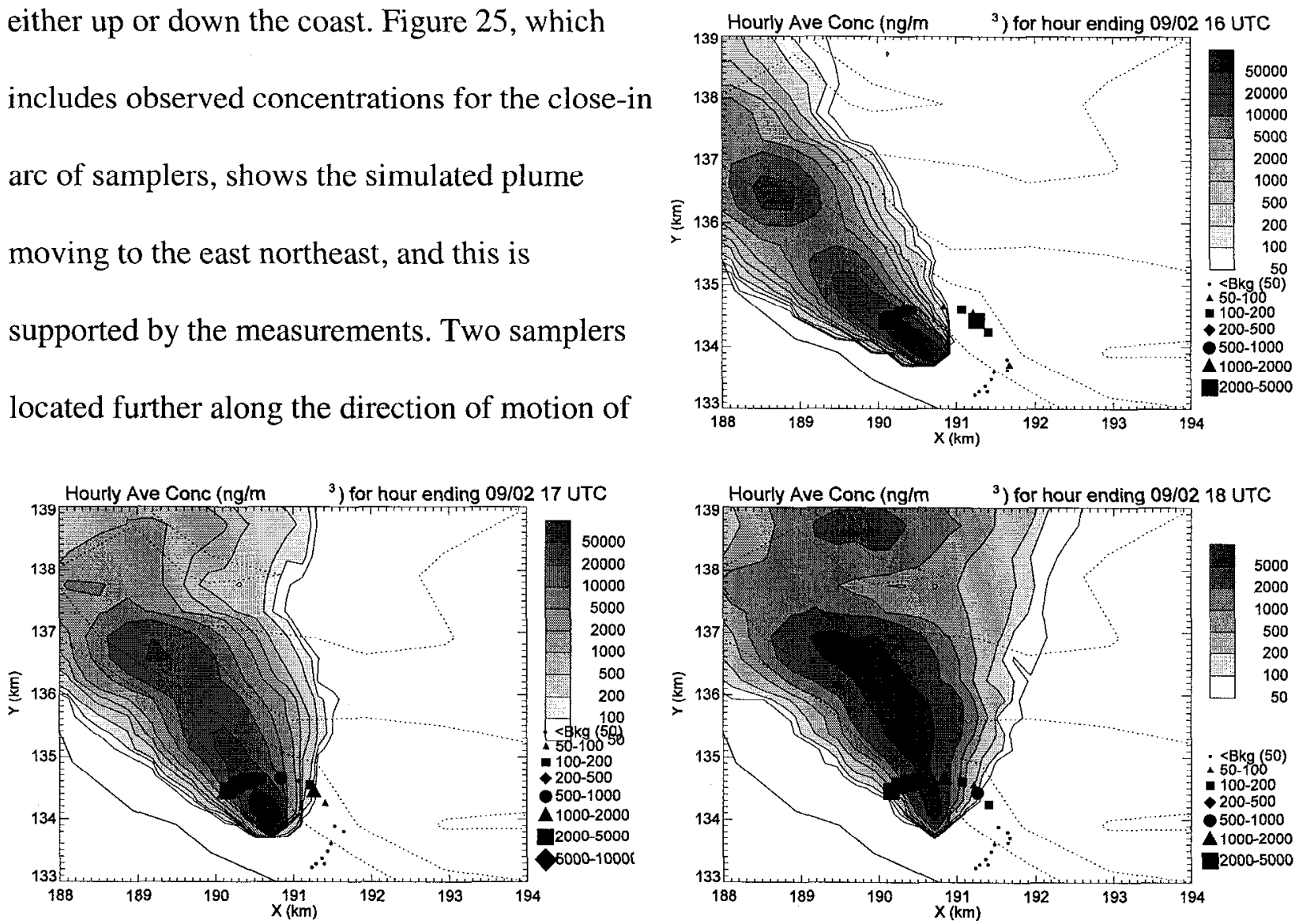

Figure 25. Hourly average $\mathrm{SF}_{6}$ concentration $\left(\mathrm{ng} / \mathrm{m}^{3}\right)$ at 9,10 and 11 am $(16,17$ and $18 \mathrm{UTC})$ for the September 2, 1986 release from Diablo Canyon showing the close in samplers. Shaded contours are calculated concentrations; symbols are corresponding measured concentrations. + indicates the release point. $\mathrm{SF}_{6}$ was released from 8-10 am and from 2-4 pm at $1.5 \mathrm{~m}$ and from $11 \mathrm{am}-1 \mathrm{pm}$ at $71 \mathrm{~m}$. 

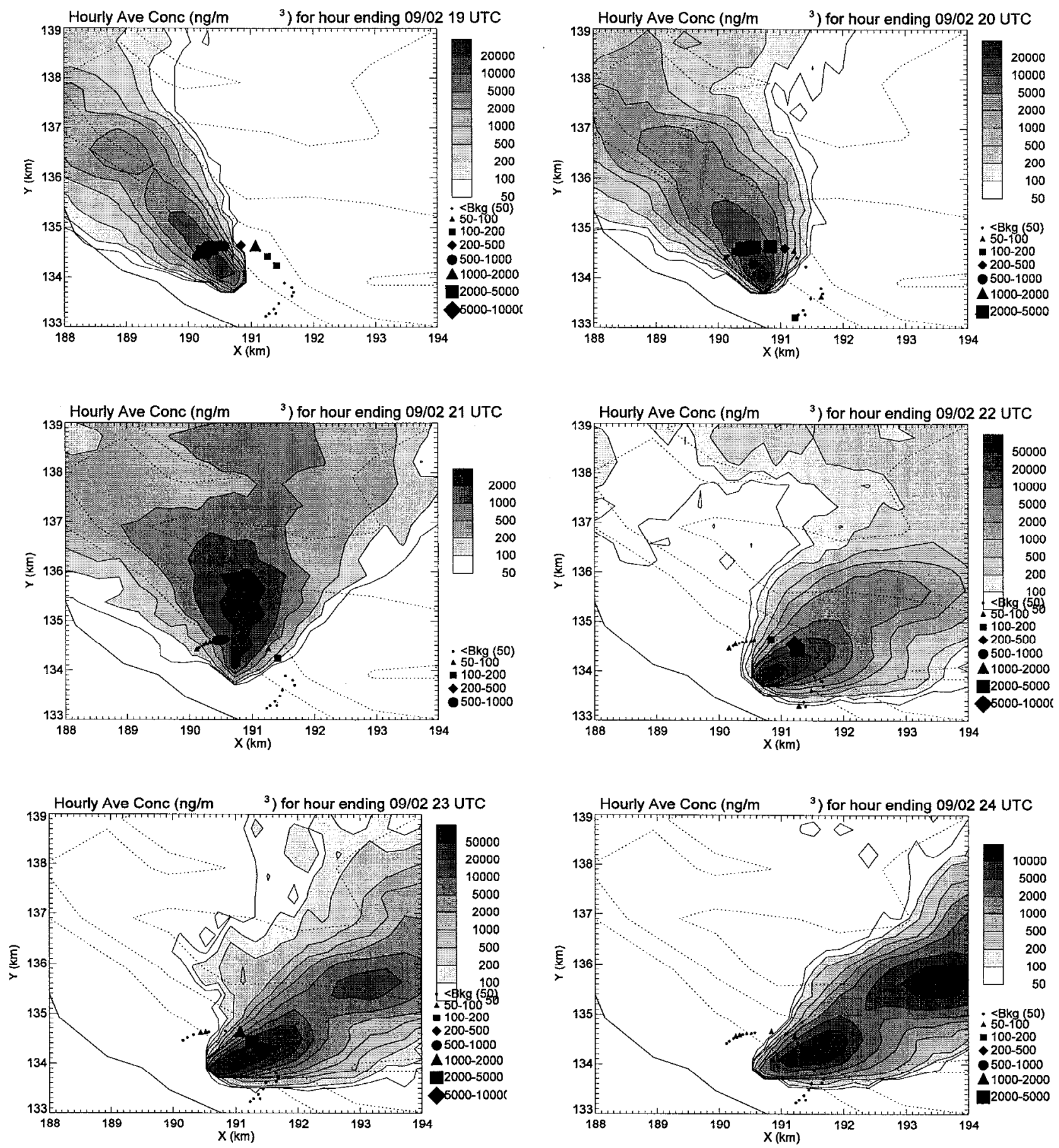

Figure 25 continued. Hourly average $\mathrm{SF}_{6}$ concentrations $\left(\mathrm{ng} / \mathrm{m}^{3}\right)$ from $19-24$ UTC (12-5 pm PDT) for the August 31, 1986 release from Diablo Canyon showing the close-in samplers. Shaded contours are calculated concentrations for the baseline run; symbols represent measured concentrations. + indicates the release point. $\mathrm{SF}_{6}$ was released from 15-17 and 21-23 UTC (8-10 am and 2-4 pm PDT) at $1.5 \mathrm{~m}$ and from $18-20 \mathrm{UTC}(11 \mathrm{am}-1 \mathrm{pm})$ at $71 \mathrm{~m}$. 
the simulated plume detected above-background $\mathrm{SF}_{6}$ concentrations, although not at the high values predicted by the simulation. The first of these samplers is the one at the top of See Canyon at an elevation of $305 \mathrm{~m}$ and the second is about $2 \mathrm{~km}$ to the east northeast at an elevation of 446 . Unfortunately, when the highest model predicted concentration occurred, at 25 UTC (6pm PDT), there is no data from this sampler.

b. Forecast Simulation

The results of the COAMPS forecast simulation for September 2, 1986 are given in Figure 26. Again the first three hours, from 16-18 UTC (9-11 am PDT), are identical to the baseline simulation. For the first release there is a significant difference between the forecast and baseline simulations; in the forecast case the plume continues to move north while in the baseline case the plume moved northwest. This is readily apparent in the 19 UTC (12pm PDT) plots where SF $_{6}$ from the first release is over the ocean while the forecast simulation's plume is over Morro Bay and north and west of the Morro Bay Power Plant. The observations support the forecast trajectory although the transport speed is too large. The forecast simulation of the first release and the observations are in excellent agreement from 20-25 UTC (1-6pm PDT). Predicted transport of $\mathrm{SF}_{6}$ eastward through the valleys between Morro Bay and Los Osos toward San Luis Obispo is in excellent agreement with the observations. The exception is that the simulated plume may be a little too far to the north in the hills, although no concentration measurements were made there.

The forecast simulation of the second $\mathrm{SF}_{6}$ release on September 2, from 18-20 UTC (11am1pm PDT), predicts a slow drift of the tracer to the north but remaining within a few $\mathrm{km}$ of the Diablo Canyon release point. Comparison of the baseline and forecast predictions in the close-in 

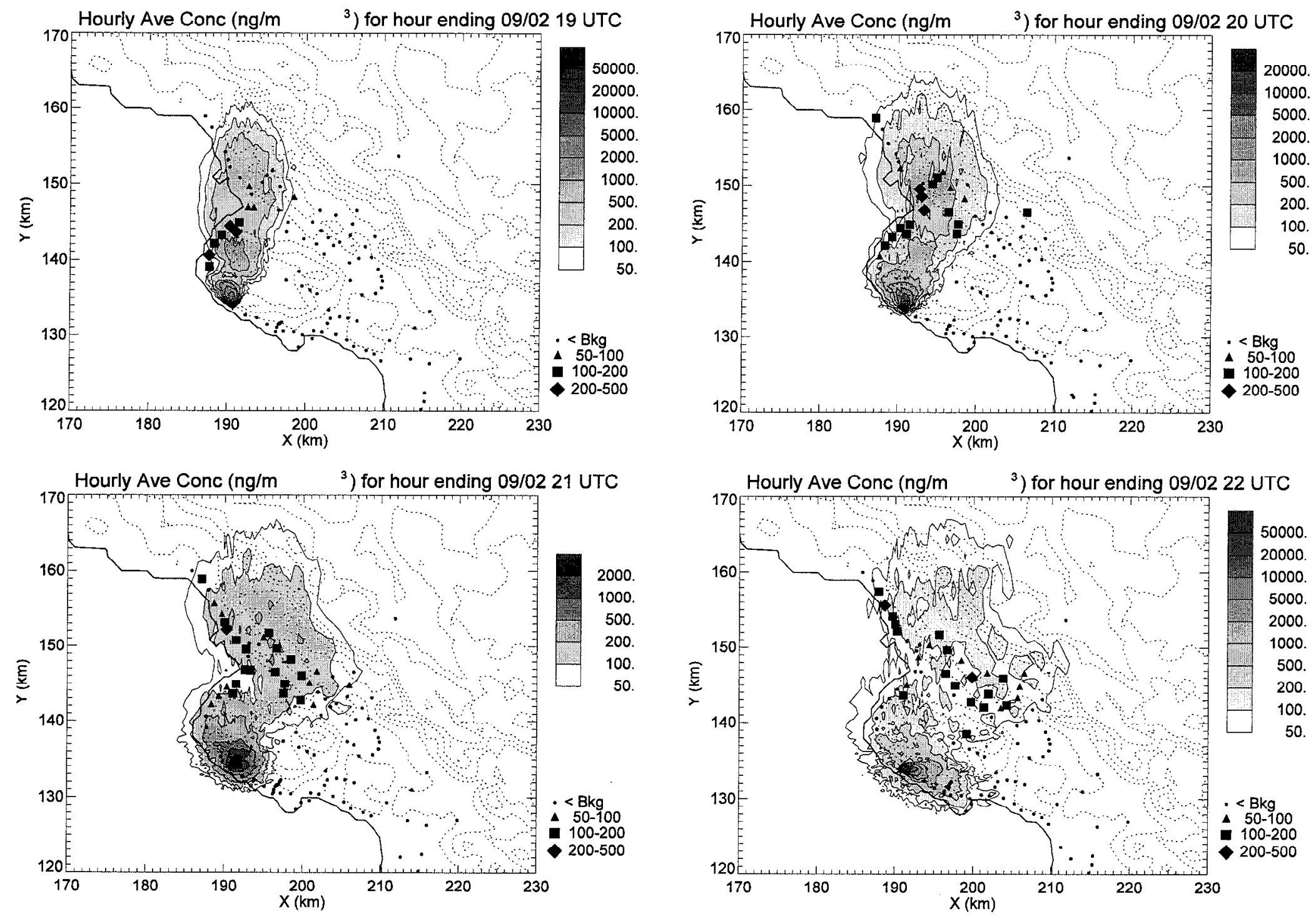

Figure 26. Hourly average $\mathrm{SF}_{6}$ concentration $\left(\mathrm{ng} / \mathrm{m}^{3}\right)$ at $19-22$ UTC (12-3 pm PDT) for the September 2, 1986 release from Diablo Canyon. Shaded contours are calculated concentrations from the forecast run with no global updates; symbols are corresponding

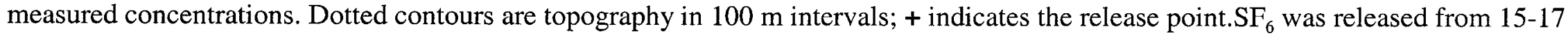
and 21-23 UTC (8-10 am and 2-4 pm PDT) at the $1.5 \mathrm{~m}$ and from 20-22 UTC (11 am-1 pm PDT) at $71 \mathrm{~m}$. 

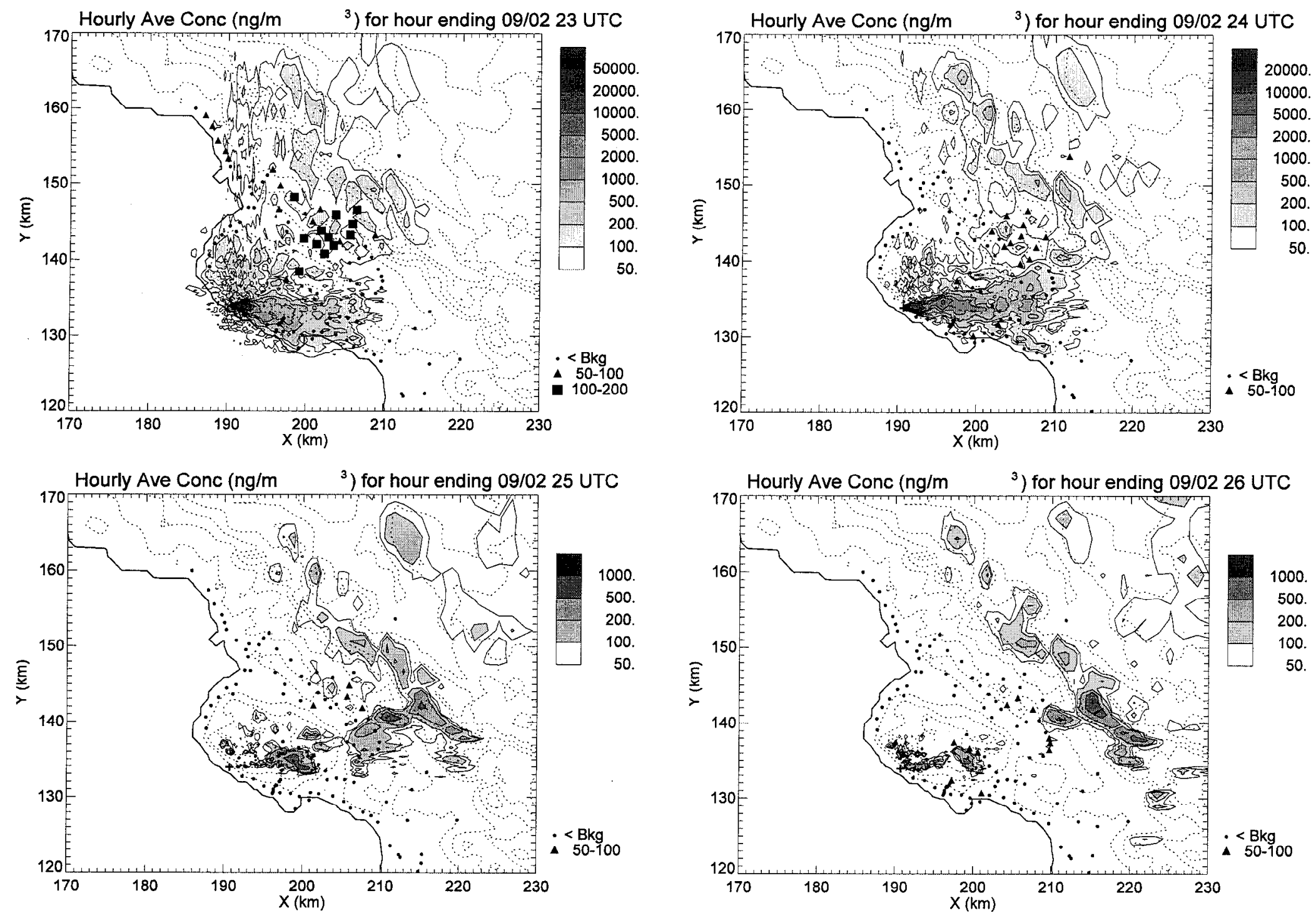

Figure 26 (continued). Hourly average $\mathrm{SF}_{6}$ concentration $\left(\mathrm{ng} / \mathrm{m}^{3}\right)$ at 23-26 UTC (4-7 pm PDT) for the September 2, 1986 release from Diablo Canyon. Shaded contours are calculated concentrations from the forecast run with no global updates; symbols are corresponding measured concentrations. Dotted contours are topography in $100 \mathrm{~m}$ intervals; + indicates the release point. $\mathrm{SF}_{6} \mathrm{was}$ released from 15-17 and 21-23 UTC (8-10 am and 2-4 pm PDT) at the $1.5 \mathrm{~m}$ and from 20-22 UTC (11 am-1 pm PDT) at $71 \mathrm{~m}$. 
plots (Figures 25 and 27) at 19 and 20 UTC (12 and 1pm PDT) shows that the baseline run transports $\mathrm{SF}_{6}$ to the northwest while the forecast simulation transports $\mathrm{SF}_{6}$ more to the north. While the baseline simulation predicts the direction better, the slower speed in the forecast run seems to agree better with the observations. Also, the parameters used to specify the initial dispersion of the release are too large. The forecast simulation for later times predicts the $\mathrm{SF}_{6}$ moves north to Los Osos and then east through the Los Osos Valley toward San Luis Obispo. This is in good agreement with the sampler data. The baseline run, with its initial westerly component for the plume, predicts transport of $\mathrm{SF}_{6}$ through the Los Osos Valley too slowly. At 24 and 25 UTC (5 and 6pm PDT) the observations and forecast simulation show the $\mathrm{SF}_{6}$ is in the eastern part of the valley while the baseline simulation still has significant concentrations of the tracer over Morro Bay and in the western part of the Los Osos Valley.

The trajectory predicted by the forecast run for the third $\mathrm{SF}_{6}$ release on September 2, 1986 is almost due east. Comparison to the close-in plots for 22-24 UTC (3-5pm PDT) in Figure 27 show that the correct trajectory is more to the northeast. At greater distances from the release point this predicted plume passes south of almost all the samplers that registered abovebackground concentrations. The baseline run seems to represent this release better, sending it over the mountain northwest of Diablo Canyon and perhaps into the Los Osos Valley west of San Luis Obispo. After 23 UTC (4pm PDT) on September 2, none of the ground samplers detected $\mathrm{SF}_{6}$ at concentrations of more than $100 \mathrm{ng} / \mathrm{m}^{3}$ making it very difficult to determine the plume location. Possibly the $\mathrm{SF}_{6}$, after going over the mountain, was transported east or northeast by the winds aloft and did not affect the surface collectors. 



Figure 27. Hourly average $\mathrm{SF}_{6}$ concentrations $\left(\mathrm{ng} / \mathrm{m}^{3}\right)$ from 19-24 UTC (12-5 pm PDT) for the September 2, 1986 release from Diablo Canyon showing the close-in samplers. Shaded contours are calculated concentrations from the forecast run; symbols represent measured concentrations. + indicates the release point. $\mathrm{SF}_{6}$ was released from 15-17 and 21-23 UTC (8-10 am and 2-4 pm PDT) at $1.5 \mathrm{~m}$ and from 18-20 UTC (11 am-1 pm) at the $71 \mathrm{~m}$. 
The simulations on September 2, when the synoptic forcing was weak, are subject to considerable variability in the local flow. The plume trajectory for the morning release was to the north or northwest, during the day the wind direction changed so that by the third release the flow was to the east northeast. During midday close to the release point the winds were very light. This rotation of the wind with time at Diablo Canyon was modeled extremely well by the baseline simulation. Nevertheless, representation of the flow over the full area affected by the tracer from the first two releases was better represented by the forecast simulation. It represented the transport of $\mathrm{SF}_{6}$ through the valleys between Morro Bay, Los Osos and San Luis Obispo especially well. By the time of the third release, the baseline simulation provided better results, although much of the $\mathrm{SF}_{6}$ in that release was not sampled by ground-based collectors.

\section{September 4,1986}

The northwest synoptic flow on September 4, 1986 was similar in direction to the regime on August 31, but the wind was much weaker. $\mathrm{SF}_{6}$ was released at a height of $1.5 \mathrm{~m}$ at Diablo Canyon from 15-23 UTC (8am-4pm PDT). Also, Freon-F3B1 was released at $1.5 \mathrm{~m}$ at Los Osos Cemetery during two periods, 15-17 UTC (8-10am PDT) and 20-23 UTC (1-4pm PDT).

a. Baseline Simulation - $\mathrm{SF}_{6}$

Results of the baseline simulation are illustrated by the hourly average $\mathrm{SF}_{6}$ concentration contours plotted in Figure 28 along with the measured concentrations. For the first several hours the tracer plume moves along the coast and over San Luis Obispo Bay in a trajectory similar to that on August 31, but the plume is only about half as long at comparable times reflecting the lower wind speed. This trajectory does not contradict the observations; however, Figure 29, which shows the simulated concentrations close to Diablo Canyon including data from the $850 \mathrm{~m}$ 

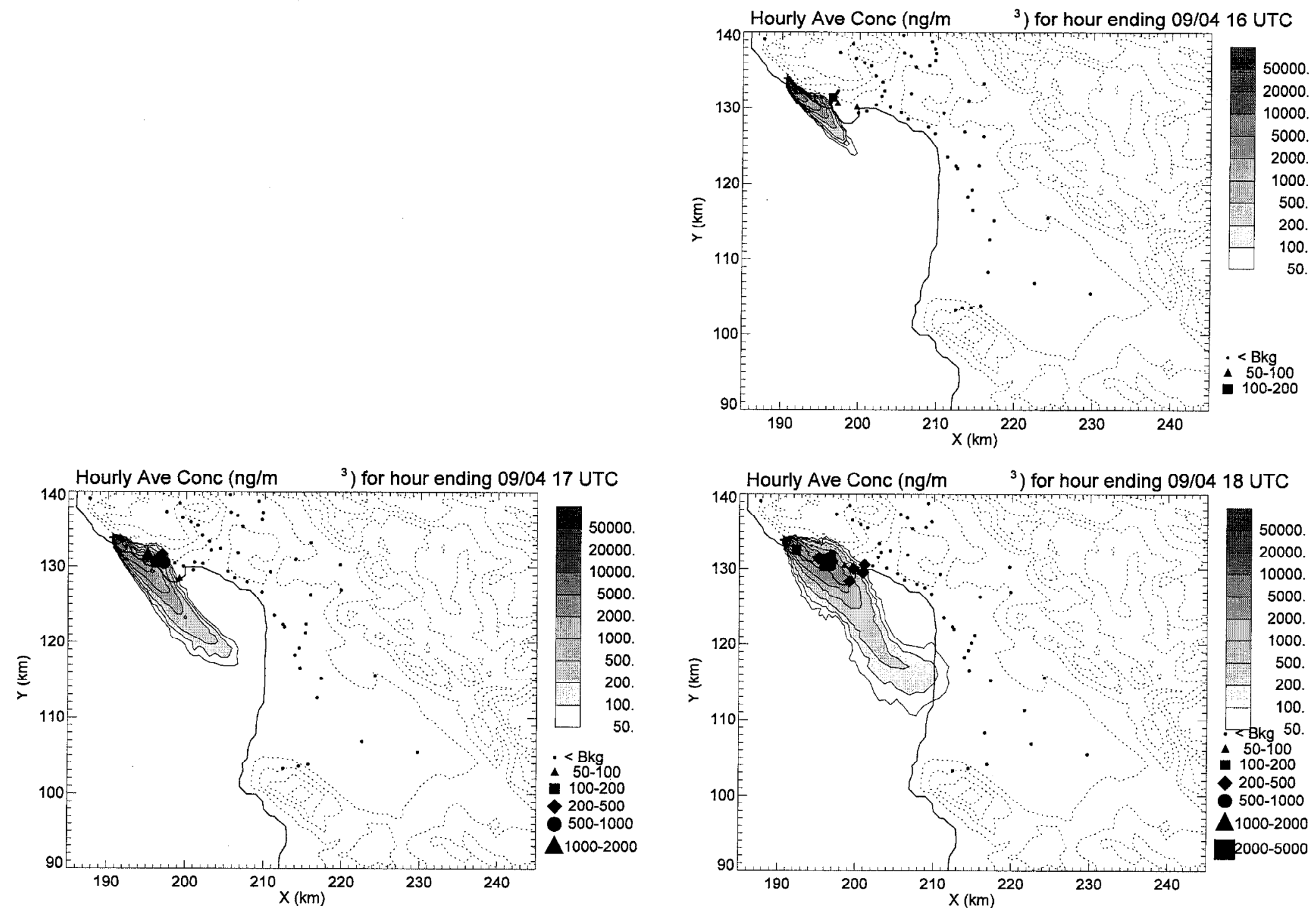

Figure 28. Hourly average $\mathrm{SF}_{6}$ concentration $\left(\mathrm{ng} / \mathrm{m}^{3}\right)$ at 16-18 UTC (9-11 am PDT) for the September 4, 1986 release from Diablo Canyon. Shaded contours are calculated concentrations; symbols are corresponding measured concentrations. Dotted contours are topography in $100 \mathrm{~m}$ intervals; + indicates the releasc point. $\mathrm{SF}_{6}$ was released from 15-23 UTC ( 8 am to 4 pm PDT). 

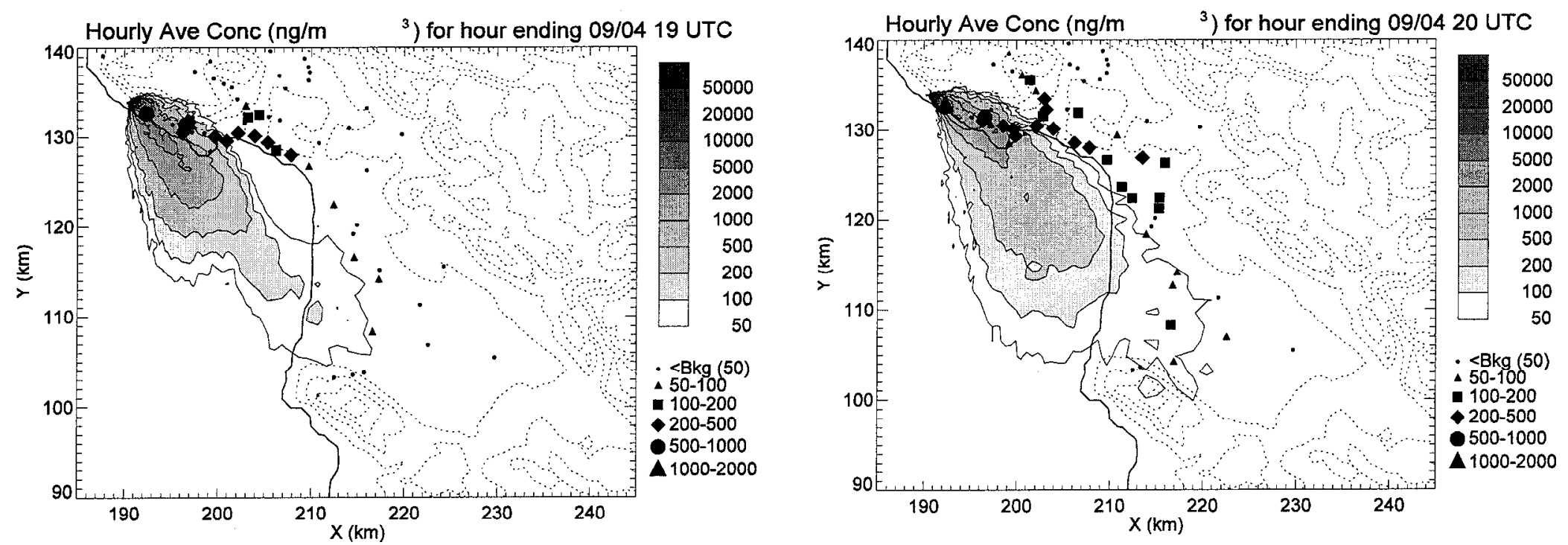

$\stackrel{P}{+}$
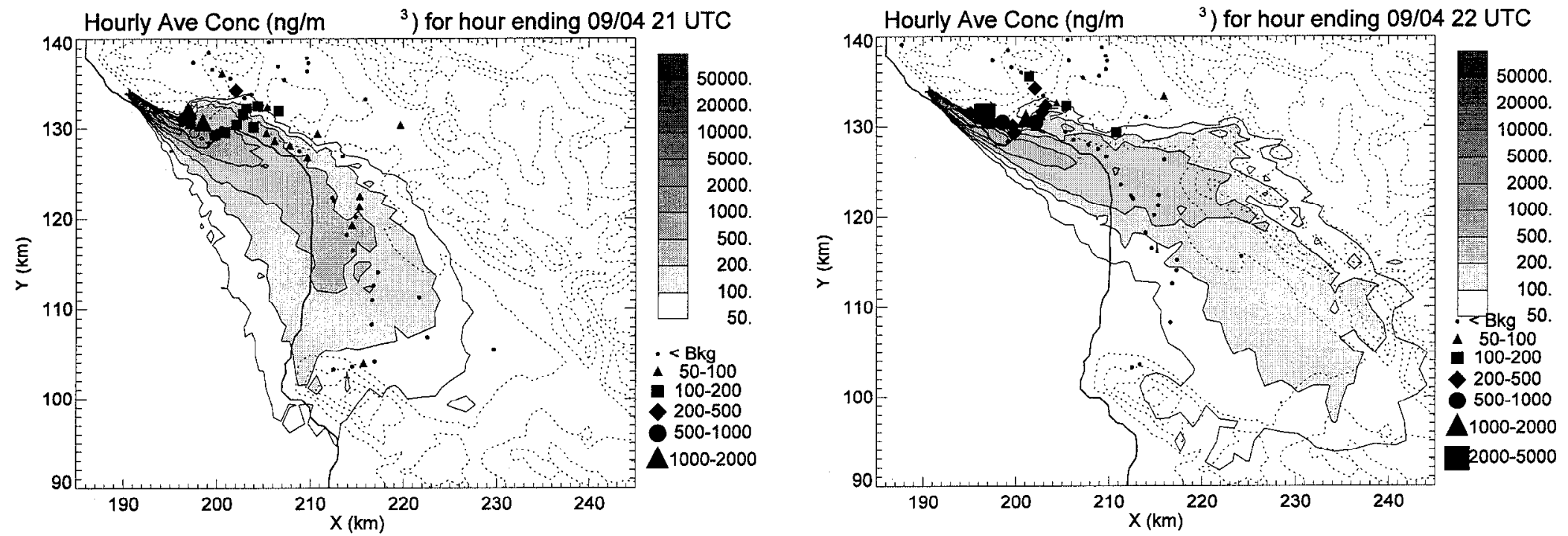

Figure 28 (continued). Hourly average $\mathrm{SF}_{6}$ concentration $\left(\mathrm{ng} / \mathrm{m}^{3}\right)$ at 19-22 UTC (12-3 pm PDT) for the September 4, 1986 release from Diablo Canyon. Shaded contours are calculated concentrations from the COAMPS baseline run with global data updates at 18 and 24 UTC ( $11 \mathrm{am}$ and $5 \mathrm{pm}$ ); symbols are corresponding measured concentrations. Dotted contours are topography in $100 \mathrm{~m}$ intervals; + indicates the release point. $\mathrm{SF}_{6}$ was released from 15-23 UTC ( 8 am to 4 pm PDT). 



Figure 29 continued. Hourly average $\mathrm{SF}_{6}$ concentrations $\left(\mathrm{ng} / \mathrm{m}^{3}\right)$ from 19-24 UTC (12-5 pm PDT) for the September 2, 1986 release from Diablo Canyon showing the close in samplers. Shaded contours are calculated concentrations; symbols are corresponding measured concentrations. + indicates the release point. $\mathrm{SF}_{6}$ was released from 15-23 UTC (8am-4pm PDT) at the ground. 
model is not able to reproduce these observations. From 19-26 UTC (12-7pm PDT) the SF $_{6}$ concentrations, measured by the samplers along the coast from Diablo Canyon nearly all the way to Pismo Beach, are consistently several times background. During most of this time the simulated plume remains south of the observed plume. Late in the day, 25-26 UTC (6-7pm PDT), the model plume has moved off to the east while samplers along the beach and in the highway 101 corridor still detect above-background concentrations of $\mathrm{SF}_{6}$.

b. Forecast Simulation - $\mathrm{SF}_{6}$

The results of the COAMPS forecast simulation for September 4, 1986 are given in Figure 30. Since the first update with global data does not occur until 18 UTC (11am PDT), the wind fields and tracer transport for the first three hours are identical to the baseline simulation. The differences between the forecast and the baseline simulations are quite small. The forecast simulation does not have the turning to the south that the update cycle induced in the baseline run. Therefore, the plume from the forecast simulation lies slightly north of the baseline plume. The forecast run also has slightly smaller speeds so the plume moves downwind a bit more slowly. The forecast simulation also does not reproduce the transport of $\mathrm{SF}_{6}$ north along the highway 101 corridor or into See Canyon. By late in the day, the released tracer has all moved far to the east, while the samplers in the coastal area between Avila Beach and Pismo Beach, along the 101 corridor, and in See Canyon are still detecting concentrations several times background.

The tendency for the forecast plume to lie slightly to the north of the baseline plume can also be seen in Figure 31, which compares the model plume just downwind of the release point with observed concentrations from the $850 \mathrm{~m}$ arc and Pecho Creek array of samplers. Otherwise the differences between the baseline and forecast simulations near the release site are small. 

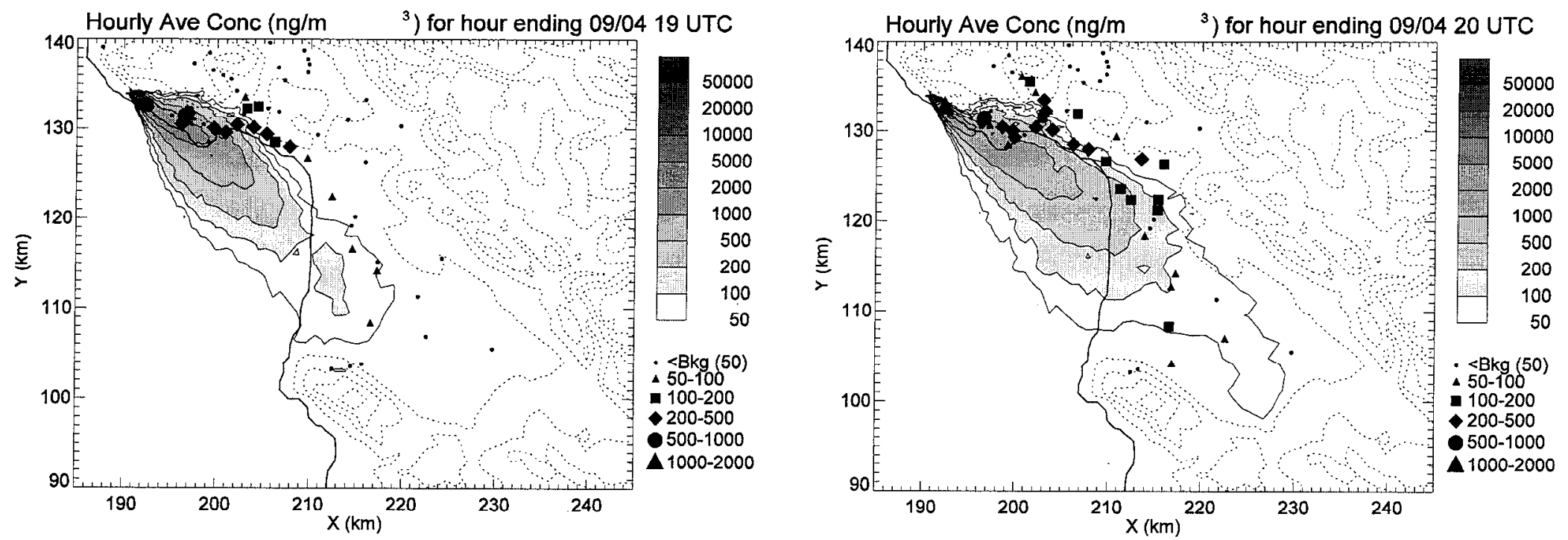

$\hat{6}$
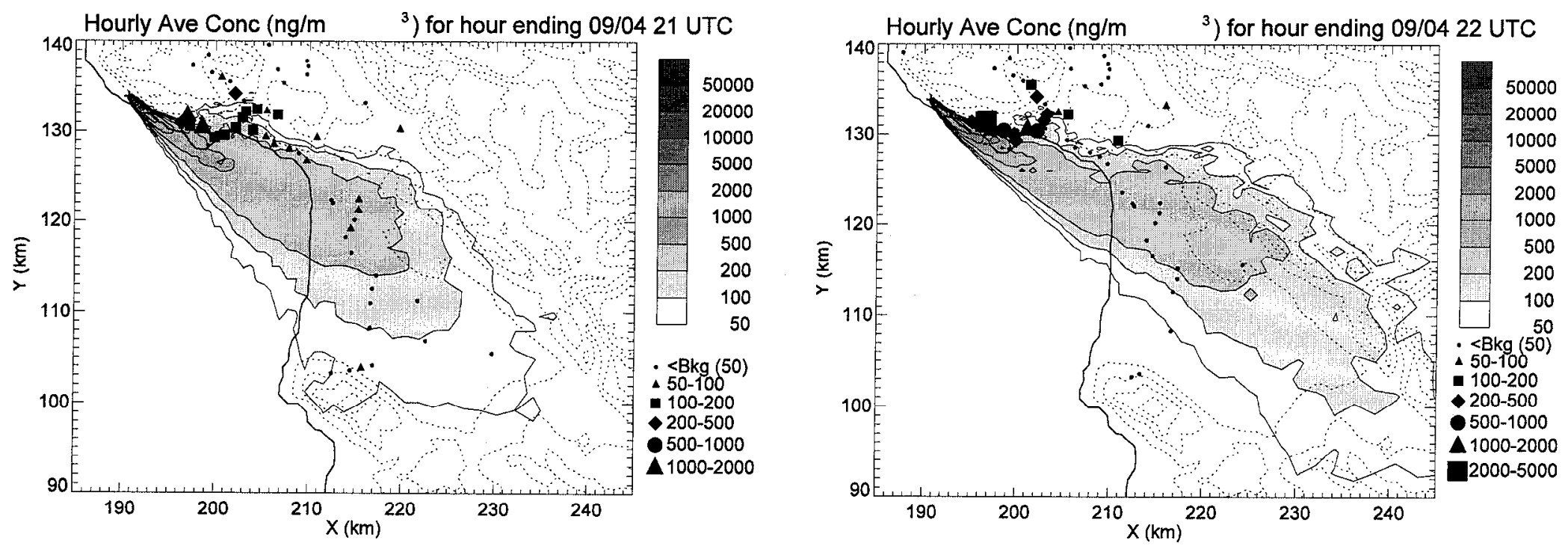

Figure 30. Hourly average $\mathrm{SF}_{6}$ concentration $\left(\mathrm{ng} / \mathrm{m}^{3}\right)$ at 19-22 UTC (12-3 pm PDT) for the September 4, 1986 release from Diablo Canyon. Shaded contours are calculated concentrations from the COAMPS forecast run with no global data updates; symbols are corresponding measured concentrations. Dotted contours are topography in $100 \mathrm{~m}$ intervals; + indicates the release point. $\mathrm{SF}_{6} \mathrm{was}$ released from 15-23 UTC ( 8 am to 4 pm PDT). 

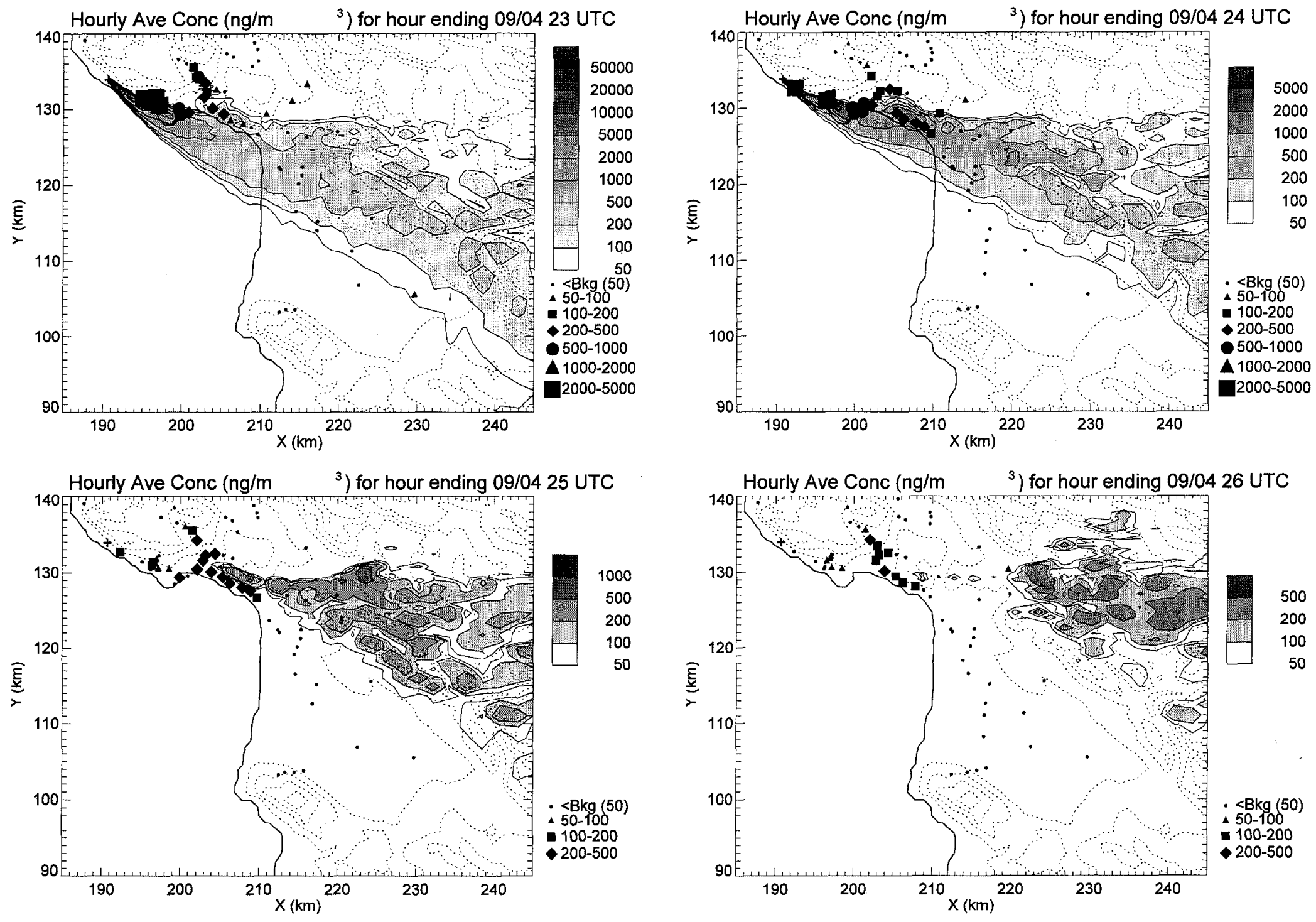

Figure 30 (continued). Hourly average $\mathrm{SF}_{6}$ concentration $\left(\mathrm{ng} / \mathrm{m}^{3}\right)$ at 23-26 UTC (4-7 pm PDT) for the September 4, 1986 release from Diablo Canyon. Shaded contours are calculated concentrations from the COAMPS forecast run with no global data updates; symbols are corresponding measured concentrations. Dotted contours are topography in $100 \mathrm{~m}$ intervals; + indicates the release point. $\mathrm{SF}_{6} \mathrm{Was}$ released from 15-23 UTC ( 8 am to 4 pm PDT). 



Figure 31. Hourly average $\mathrm{SF}_{6}$ concentrations $\left(\mathrm{ng} / \mathrm{m}^{3}\right)$ from $12-5 \mathrm{pm}$ (19-24 UTC) for the September 2, 1986 release from Diablo Canyon showing the close in samplers. Shaded contours are calculated concentrations; symbols are corresponding measured concentrations. + indicates the release point. $\mathrm{SF}_{6}$ was released from $8 \mathrm{am}-4 \mathrm{pm}$ at the ground. 


\section{c. Baseline Simulation - Freon-F3B1}

On September 4, 1986 besides the release of $\mathrm{SF}_{6}$ at Diablo Canyon, Freon-F3B1 was released at the Los Osos Cemetery. This release is interesting because the release site is north of the mountains and east of Diablo Canyon. Freon released from Los Osos Cemetery stayed north and east of the mountains while the Diablo Canyon's $\mathrm{SF}_{6}$ tracer went south and east on the other side of the mountains. The two release periods for Freon at Los Osos Cemetery were from 15-17 UTC (8-10 am PDT) and from 20-23 UTC (1-4 pm PDT). The hourly predicted and measured concentration data are presented in Figure 32. Note that the mass release rate for Freon was 6-10 times the rate for $\mathrm{SF}_{6}$ and that the background concentration for Freon is $800 \mathrm{ng} / \mathrm{m}^{3}$ while for $\mathrm{SF}_{6}$ it is $50 \mathrm{ng} / \mathrm{m}^{3}$.

Measured concentration data for Freon is much more difficult to interpret than for $\mathrm{SF}_{6}$. Fewer samplers have above-background readings and often the above-background observations are interspersed between sampler sites with below-background concentrations. In the baseline simulation Freon from the first release moves east southeast from the release site through the Los Osos Valley and into the highway 101 corridor. At 17 and 18 UTC (10 and 11 am PDT) the simulated transport is a bit slow. The plume does not progress quite as far as the high concentrations measured in the north end of the highway 101 corridor at 17 UTC (9am PDT). Also, the model retains elevated concentrations close to the release site too long after the release stops at 18 UTC (11am PDT). At 18 UTC the observed Freon is oriented mainly north/south from San Luis Obispo through the highway 101 corridor, with many samplers there measuring above-background concentrations. In the simulation Freon has not moved quite far enough east and north into San Luis Obispo and has diffused south up the mountainside too much. Also, at 

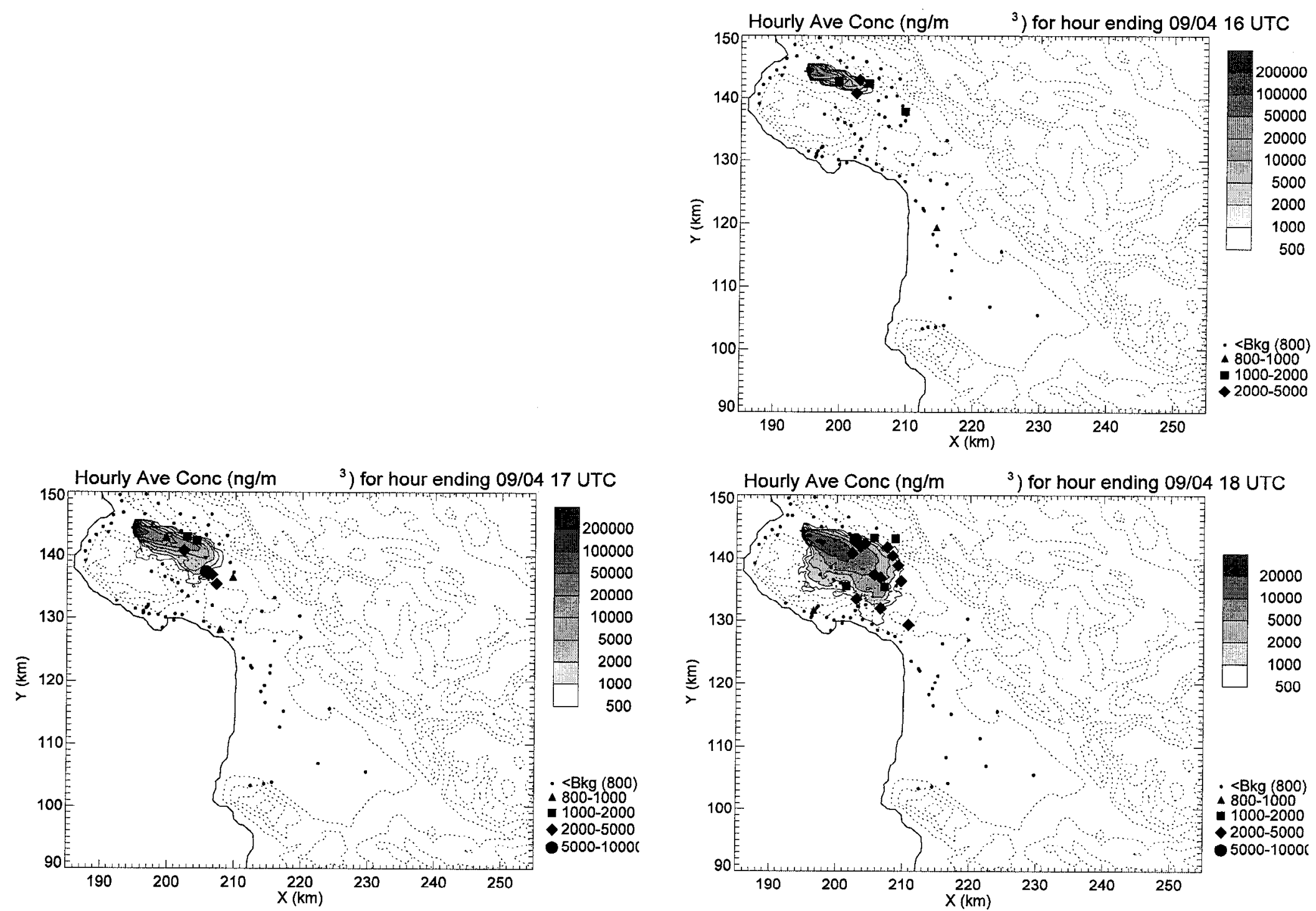

Figure 32. Hourly average Freon-F3B1 concentration $\left(\mathrm{ng} / \mathrm{m}^{3}\right)$ at 16,17 , and $18 \mathrm{UTC}(9,10$, and 11 am PDT) for the September 4, 1986 release from Los Osos Cemetery. Shaded contours are calculated concentrations; symbols are corresponding measured concentrations. Dotted contours are topography in $100 \mathrm{~m}$ intervals; + indicates the relcasc point. Freon was released from 15-17 UTC (8-10 am PDT) and from 20-23 UTC (1-4 pm PDT). 

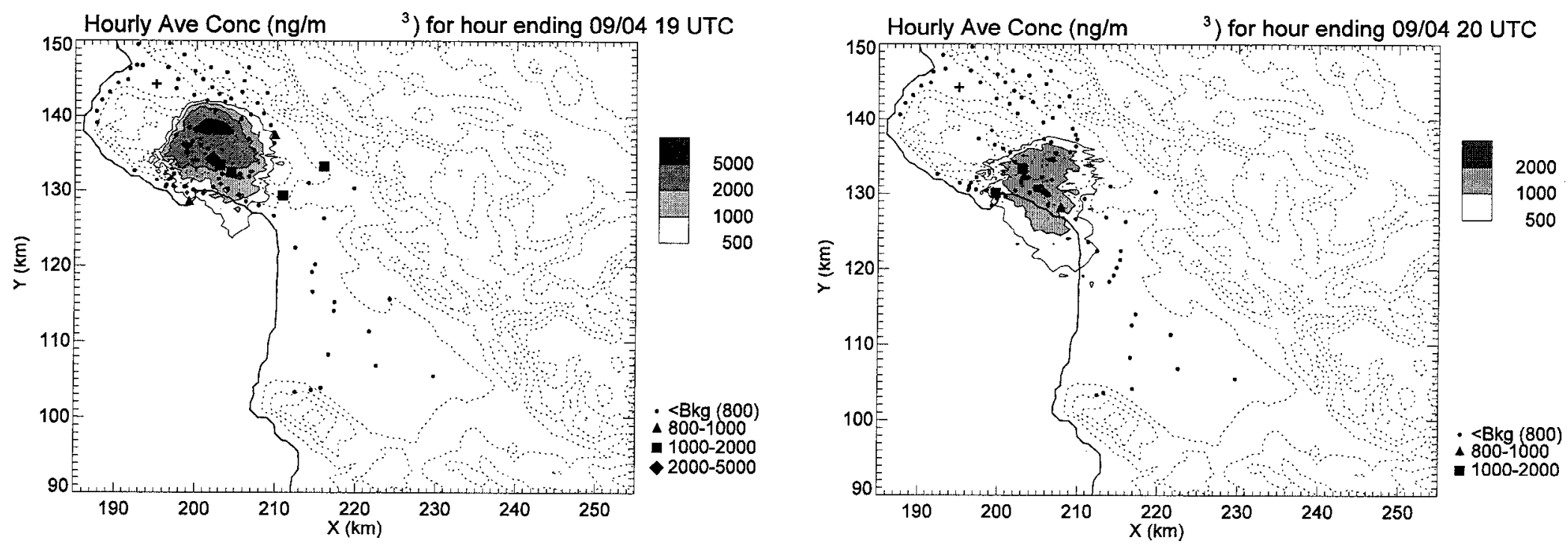

$\dddot{A}$
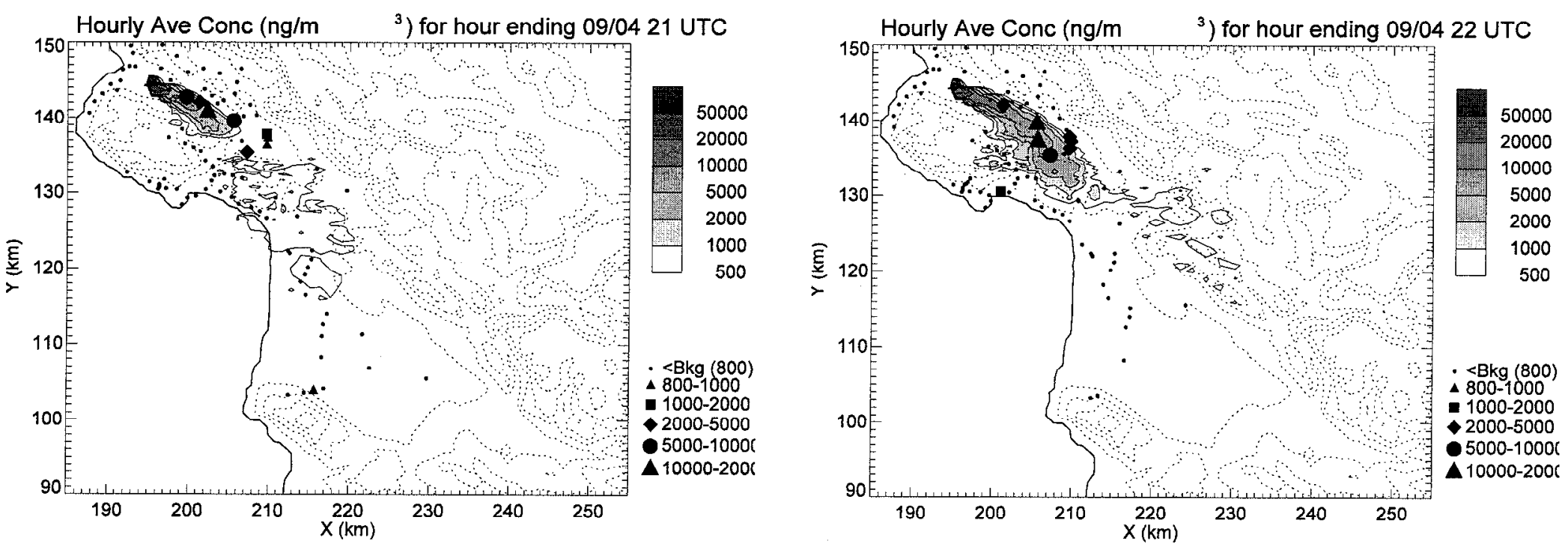

Figure 32 (continued). Hourly average Freon-F3B1 concentration $\left(\mathrm{ng} / \mathrm{m}^{3}\right)$ at 19-22 UTC (12-3 pm PDT) for the September 4,1986 release from Los Osos Cemetery. Shaded contours are calculated concentrations from the COAMPS baseline run with global updates at $11 \mathrm{am}$ and $5 \mathrm{pm}$; symbols are corresponding measured concentrations. Dotted contours are topography in $100 \mathrm{~m}$ intervals; + indicates the release point. Freon was released from 15-17 UTC (8-10 am PDT) and from 20-23 UTC (1-4 pm PDT). 

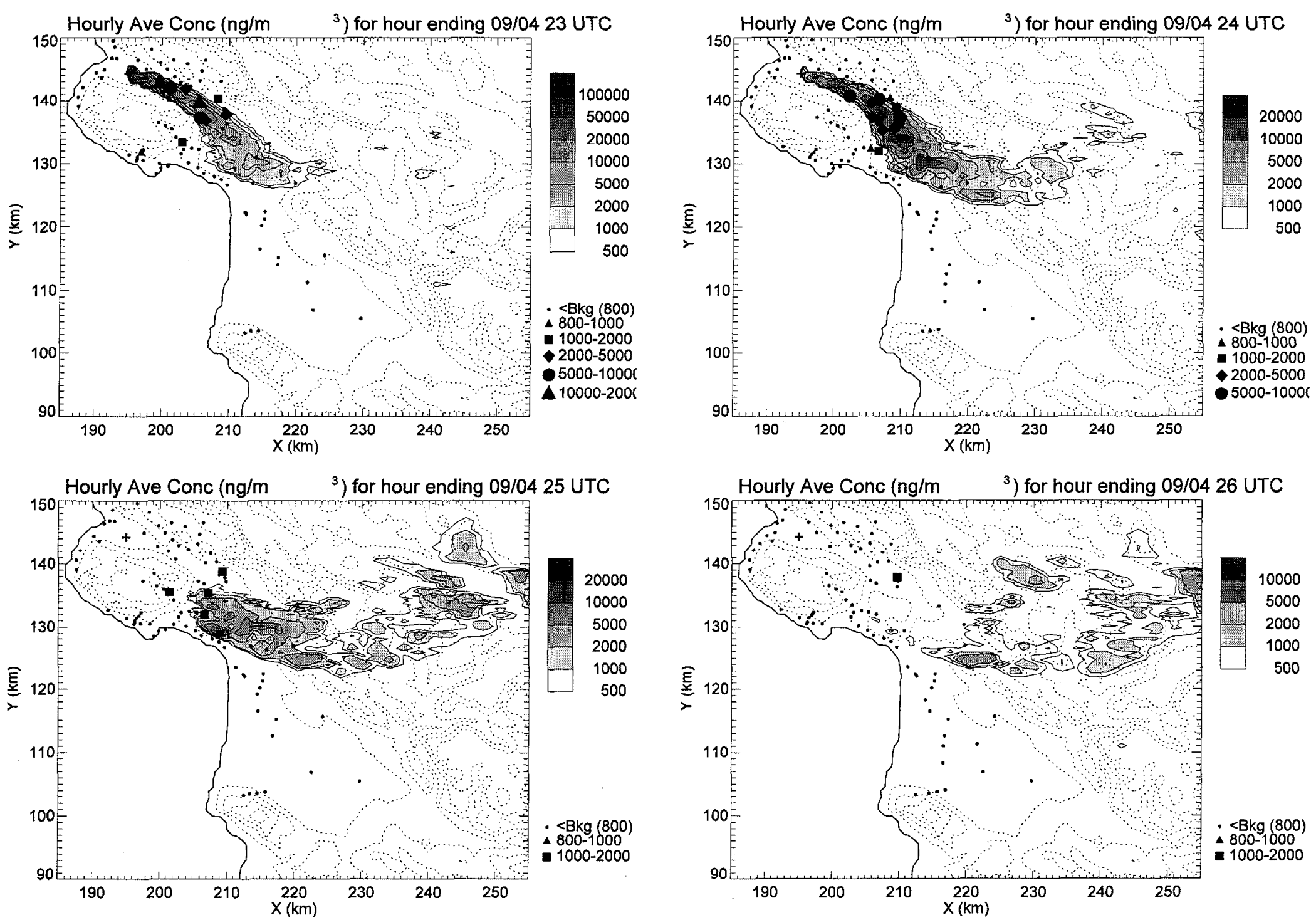

Figure 32 (continued). Hourly average Freon-F3B1 concentration $\left(\mathrm{ng} / \mathrm{m}^{3}\right)$ at $23-26$ UTC (4-7 pm PDT) for the September 4, 1986 release from Los Osos Cemetery. Shaded contours are calculated concentrations from the COAMPS baseline run with global updates at $11 \mathrm{am}$ and $5 \mathrm{pm}$; symbols are corresponding measured concentrations. Dotted contours are topography in $100 \mathrm{~m}$ intervals; + indicates the release point. Freon was released from 15-17 UTC (8-10 am PDT) and from 20-23 UTC (1-4 pm PDT). 
19 UTC (12pm PDT) most of these sites measured below-background concentrations of Freon. It is interesting that at 19 and 20 UTC (12 and 1pm PDT) some samplers in the southern end of the 101 corridor measured above-background concentrations of both $\mathrm{SF}_{6}$ and Freon. This implies transport and diffusion of tracers into this region from both the north and the south. By 20 UTC (1pm PDT) the first release of Freon has dispersed into the atmosphere so that it is no longer detectable at above-background concentrations.

The second release of Freon from Los Osos Cemetery starting at 20 UTC (1pm PDT) follows a similar trajectory to the first release through the Los Osos Valley. According to the observations, Freon in the afternoon release moves more rapidly through the Los Osos Valley than Freon in the morning release. The baseline simulation seems to underestimate the downwind transport in the afternoon. The plume also passes mainly to the north and east of the highway 101 corridor. The prediction is very good in the San Luis Obispo area at 24 UTC (5pm PDT). However, Freon is again not clearing out of the release area as rapidly as the observations suggest. Also, the downwind end of the plume is either too far south or east because it overlies several sampler sites that did not detect Freon at above-background concentrations. By 26 UTC (7pm PDT) all the Freon has moved east of the experimental area in agreement with the detection of only below-background concentrations.

\section{d. Forecast Simulation - Freon-F3B1}

The results of the COAMPS forecast simulation for September 4, 1986 releases of Freon are given in Figure 33. Again the first three hours, from 16-18 UTC (9-11am PDT), are identical to the baseline simulation; this covers most of the first release. At 19 and 20 UTC (12 and 1pm PDT) the baseline simulation plume is slightly west and south of the forecast simulation plume. 

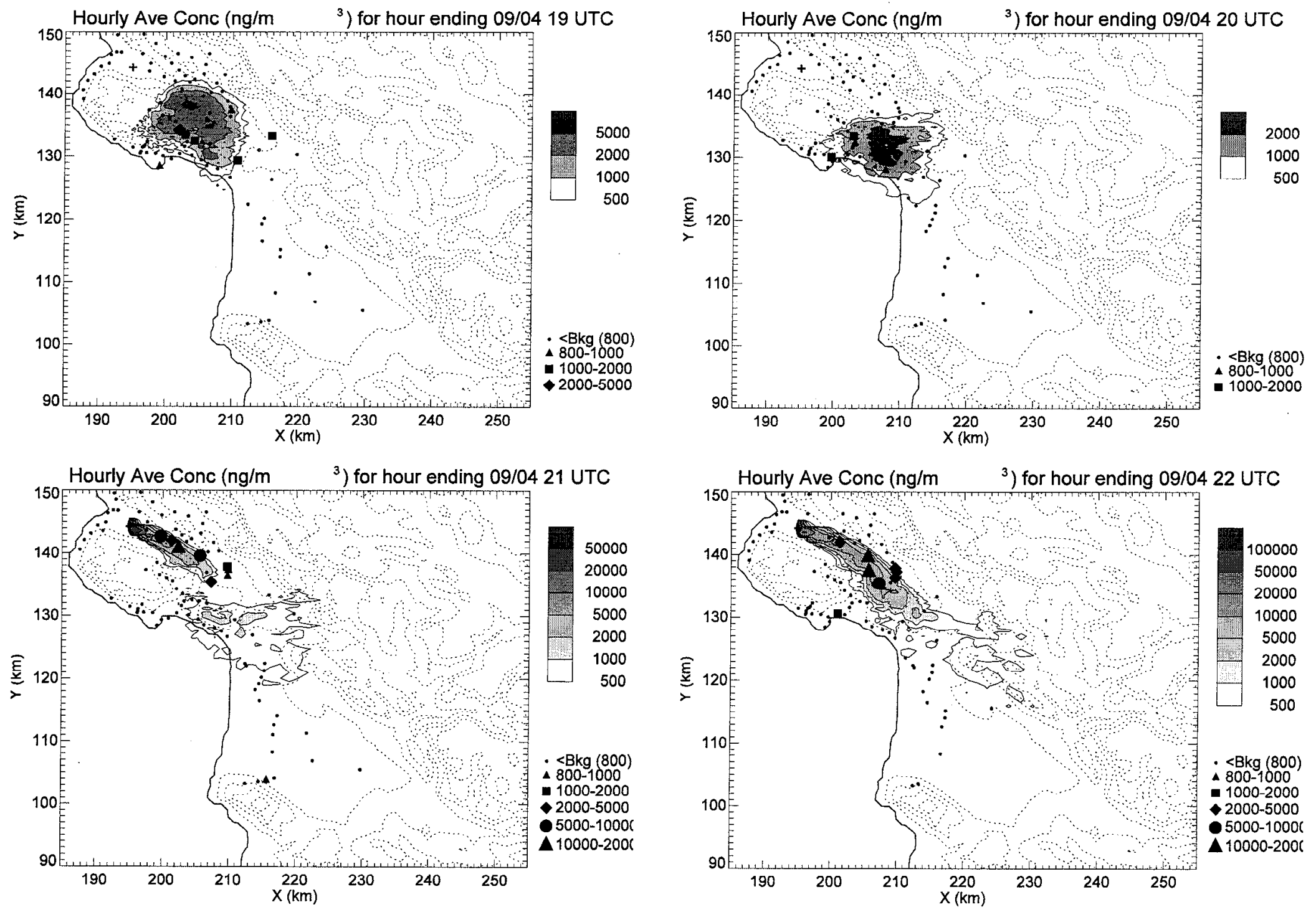

Figure 33. Hourly average Freon-F3B1 concentration (ng/m ${ }^{3}$ ) at 19-22 UTC (12-3 pm PDT) for the September 4, 1986 release from Los Osos Cemetery. Shaded contours are calculated concentrations from the COAMPS forecast run with no global updates; symbols are corresponding measured concentrations. Dotted contours are topography in $100 \mathrm{~m}$ intervals; + indicates the release point. Freon was released from 15-17 UTC (8-10 am PDT) and from 20-23 UTC (1-4 pm PDT). 

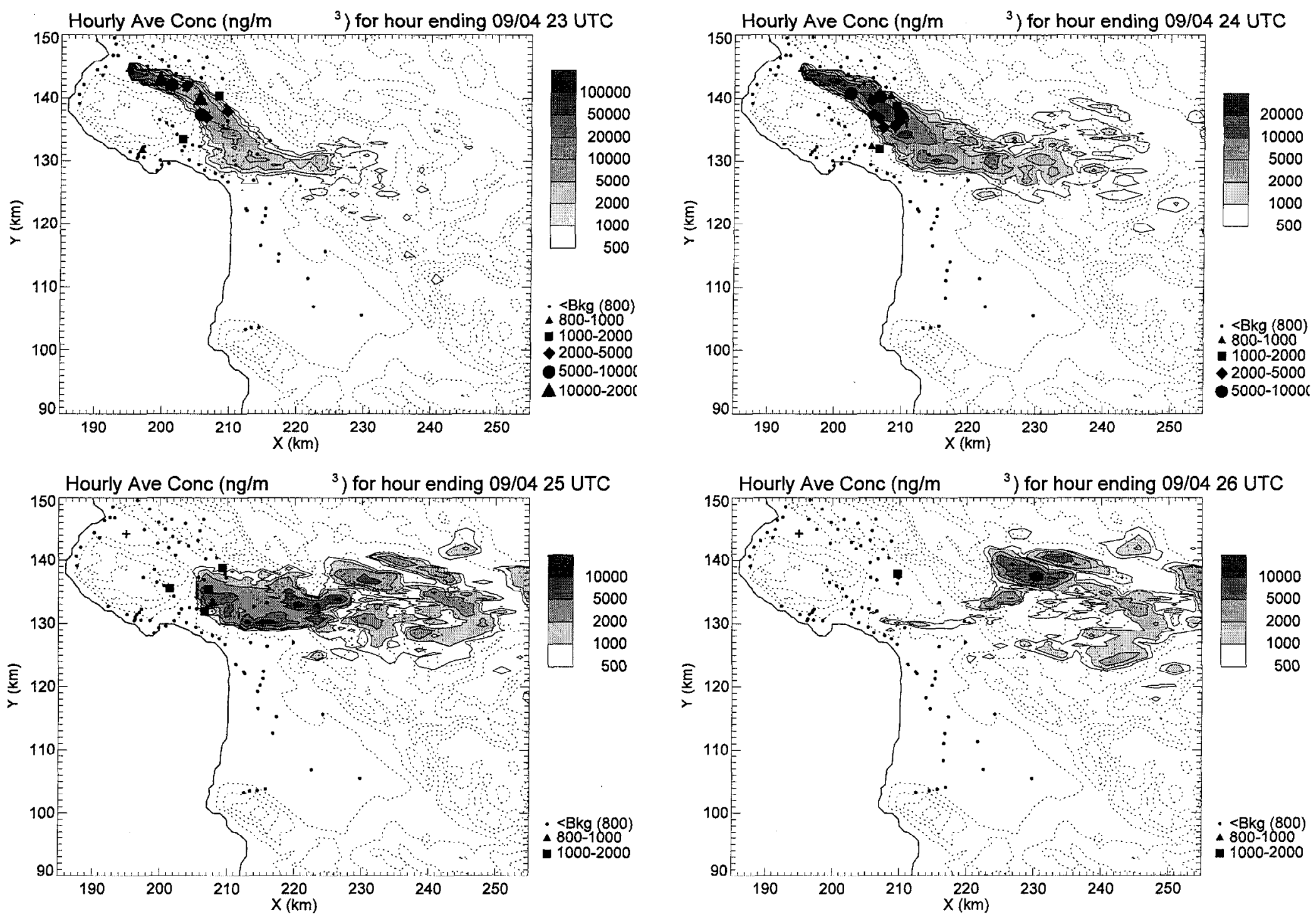

Figure 33 (continued). Hourly average Freon-F3B1 concentration $\left(\mathrm{ng} / \mathrm{m}^{3}\right)$ at $23-26$ UTC (4-7 pm PDT) for the September 4, 1986 release from Los Osos Cemetery. Shaded contours are calculated concentrations from the COAMPS forecast run with no global updates; symbols are corresponding measured concentrations. Dotted contours are topography in $100 \mathrm{~m}$ intervals; + indicates the release point. Freon was released from 15-17 UTC (8-10 am PDT) and from 20-23 UTC (1-4 pm PDT). 
This corresponds with the tendency seen in the $\mathrm{SF}_{6}$ release for the update cycle at 18 UTC (11am PDT) to deflect the winds to the south. The observations correlate equally well (or poorly) with either simulation.

The forecast simulation of the second Freon release also gives a plume trajectory that is very similar to the baseline case. Again the forecast simulation's plume has a trajectory that is a little north of the baseline trajectory and a slightly increased transport speed. The increase in speed may be a small improvement in relation to the observations during the first hour ending at 21 UTC (2pm PDT). The agreement between simulations and observations is excellent at 23 and 24 UTC (4 and 5pm PDT). For the area south and east of San Luis Obispo, the observed belowbackground concentrations are difficult to explain. The Freon had to go somewhere. Perhaps vertical diffusion reduced the surface concentrations, or perhaps the plume took a more easterly track after passing over south San Luis Obispo and stayed over the hills where no samplers are located. Nevertheless, the model simulations of the Freon releases are in excellent agreement with the observations.

\section{Conclusions}

COAMPS/LODI's simulations of the Dopptex tracer experiment on August 31, September 2, and September 4, 1986 had mixed results. The August 31 simulations of tracer concentrations differed significantly from the measured concentrations. The simulated plume trajectory was south of the region where samples had above-background concentrations. In particular, the model did not predict transport of $\mathrm{SF}_{6}$ north along highway 101 and into See Canyon. For the morning release, the models predicted rapid transport of $\mathrm{SF}_{6}$ away from the release point while observations suggested much of the tracer stayed close to Diablo Canyon for 1-2 hours. The 
September 2 simulations agreed very well with the measurements. The model accurately predicted the changing wind direction from north northwest to east northeast at the release point. Also, COAMPS/LODI, especially the forecast simulation, predicted the advection of tracer over Morro Bay and through the Los Osos Valley toward San Luis Obispo in excellent agreement with the observations. The model predicted $\mathrm{SF}_{6}$ transport from Diablo Canyon on September 4 had defects similar to those on August 31, a trajectory too far south and very limited intrusion of tracer north of Avila Beach along highway 101 and into See Canyon. On the other hand, simulations of the Freon release from Los Osos Cemetery corresponded well with the observations. The moderate success of the model in simulating these tracer experiments is a little surprising since these calculations relied solely on global reanalysis data and used no local meteorology at all.

COAMPS's inability to generate southerly winds through the highway. 101 corridor is a symptom of its underestimate of the sea breeze. The weak sea breeze correlates with a small diurnal range of air temperature (highest maximum temperatures about $84^{\circ} \mathrm{F}$ ), perhaps caused by either an underestimate of surface solar heating or an overestimate of surface wetness. The sea breeze is more poorly predicted in the baseline simulation that includes incremental updates with global-scale data than in the forecast run. Fractional surface wetness is affected by the update cycle. Interpolation along the coastline involves ocean grid points where surface wetness is 1 , and the surface wetness on COAMPS's inner nest is significantly increased by the update cycle. This is an issue that requires further investigation.

Comparison of simulated tracer plumes with observed concentration patterns near the Diablo Canyon relcase site suggests that initial diffusion of the plume was overstated by the assumed 
emission parameters. Also, COAMPS provides data permitting specification of eddy diffusion parameters in LODI. Both issues require additional research.

Results reported here are the first step in a data assimilation study to investigate how local meteorological data can enhance the accuracy of prognostic wind fields and the precision of concentration predictions. Since the local data does not extend vertically through the entire atmosphere and since the horizontal resolution is less than the model's resolution, new techniques are required to use the local surface and low altitude wind and temperature measurements. Also, quantitative methods should be used to assess the accuracy of the models. 


\section{REFERENCES}

Thuillier, R. H., 1987: Incorporation of Doppler Acoustic Rada into a Dispersion Model, Phase I - Model Development, Pacific Gas and Electric Company, Research and Development Report 009.5-87.6.

Thuillier, R. H., 1988a: Incorporation of Doppler Acoustic Rada into a Dispersion Model, Phase II - Field Experiment, Pacific Gas and Electric Company, Research and Development Report 009.5-88.3.

Thuillier, R. H., 1988b: Incorporation of Doppler Acoustic Rada into a Dispersion Model, Phase III - Data Analysis and Model Evaluation, Volume 1, Pacific Gas and Electric Company, Research and Development Report 009.5-88.4.

Thuillier, R. H., 1988c: Incorporation of Doppler Acoustic Rada into a Dispersion Model, Phase III - Data Analysis and Model Evaluation, Volume 2, Appendices, Pacific Gas and Electric Company, Research and Development Report 009.5-88.4A.

Leone, J. M. Jr., J. S. Nasstrom, and D. M. Maddix, 1998: LODI (Livermore Operational Dispersion Integrator) User's Guide, LLNL Report No. (in preparation).

Hodur, R. M., 1997: The Naval Research Laboratory's Coupled Ocean/Atmosphere Mesoscale Prediction System (COAMPS). Mon. Wea., Rev., 125, 1414-1430.

Klemp, J., and R. Wilhelmson, 1978: The simulation of three-dimensional convective storm dynamics. J. Atmos. Sci., 35, 1070-1096.

Hogan, T. F., and T.E . Rosmond, 1991: The description of the U. S. Navy operational Global Atmospheric Prediction System's spectral forecast model. Mon. Wea. Rev., 119, 1786-1815.

Kalnay, E., M. Kanamitsu, R. Kistler, W. Collins, D. Deaven, L. Gandin, M. Iredell, S. Saha, G. White, J. Woollen, Y. Zhu, M. Chelliah, W. Ebisuzaki, W. Higgins, J. Janowiak, K. C. Mo, C. Ropelewski, J. Wang, A. Leetmaa, R. Reynolds, R. Jenne, and D. Joseph, 1996: The NCEP/NCAR 40-year reanalysis project. Bull. Amer. Meteor. Soc., 77, 437-471.

Lorenc, A. C., 1986: Analysis methods for numerical weather prediction. Quart. J. Roy. Meteor. Soc., 112, 1177-1194. 